\title{
Molecular Targets of Cannabidiol in Neurological Disorders
}

\author{
Clementino Ibeas Bih $^{1}$ • Tong Chen ${ }^{1}$ - Alistair V. W. Nunn ${ }^{2} \cdot$ Michaël Bazelot $^{1,3}$ • \\ Mark Dallas $^{1} \cdot$ Benjamin J. Whalley ${ }^{1}$
}

Published online: 12 August 2015

(C) The American Society for Experimental NeuroTherapeutics, Inc. 2015

\begin{abstract}
Cannabis has a long history of anecdotal medicinal use and limited licensed medicinal use. Until recently, alleged clinical effects from anecdotal reports and the use of licensed cannabinoid medicines are most likely mediated by tetrahydrocannabinol by virtue of: 1) this cannabinoid being present in the most significant quantities in these preparations; and b) the proportion:potency relationship between tetrahydrocannabinol and other plant cannabinoids derived from cannabis. However, there has recently been considerable interest in the therapeutic potential for the plant cannabinoid, cannabidiol (CBD), in neurological disorders but the current evidence suggests that $\mathrm{CBD}$ does not directly interact with the endocannabinoid system except in vitro at supraphysiological concentrations. Thus, as further evidence for CBD's beneficial effects in neurological disease emerges, there remains an urgent need to establish the molecular targets through which it exerts its therapeutic effects. Here, we conducted a systematic search of the extant literature for original articles describing the molecular pharmacology of CBD. We critically appraised the results for the validity of the molecular targets proposed. Thereafter, we considered whether the molecular targets of CBD identified hold therapeutic potential in relevant neurological diseases. The molecular targets identified include numerous classical ion channels, receptors, transporters, and enzymes. Some CBD effects at these targets in in vitro assays only manifest at high concentrations, which may be difficult to achieve in vivo, particularly given CBD's relatively
\end{abstract}

Benjamin J. Whalley

b.j.whalley@reading.ac.uk

1 School of Chemistry, Food and Nutritional Sciences, and Pharmacy, University of Reading, Whiteknights, Reading RG6 6AP, UK

2 Broadmind Science Ltd, 47 Bow Field, Hook, Hants RG27 9SA, UK

3 GW Pharmaceuticals Ltd, Sovereign House, Vision Park, Chivers Way, Histon, Cambridge CB24 9BZ, UK poor bioavailability. Moreover, several targets were asserted through experimental designs that demonstrate only correlation with a given target rather than a causal proof. When the molecular targets of CBD that were physiologically plausible were considered for their potential for exploitation in neurological therapeutics, the results were variable. In some cases, the targets identified had little or no established link to the diseases considered. In others, molecular targets of CBD were entirely consistent with those already actively exploited in relevant, clinically used, neurological treatments. Finally, CBD was found to act upon a number of targets that are linked to neurological therapeutics but that its actions were not consistent withmodulation of such targets that would derive a therapeutically beneficial outcome. Overall, we find that while $>65$ discrete molecular targets have been reported in the literature for $\mathrm{CBD}$, a relatively limited number represent plausible targets for the drug's action in neurological disorders when judged by the criteria we set. We conclude that $\mathrm{CBD}$ is very unlikely to exert effects in neurological diseases through modulation of the endocannabinoid system. Moreover, a number of other molecular targets of CBD reported in the literature are unlikely to be of relevance owing to effects only being observed at supraphysiological concentrations. Of interest and after excluding unlikely and implausible targets, the remaining molecular targets of CBD with plausible evidence for involvement in therapeutic effects in neurological disorders (e.g., voltage-dependent anion channel $1, \mathrm{G}$ protein-coupled receptor 55, CaV3.x, etc.) are associated with either the regulation of, or responses to changes in, intracellular calcium levels. While no causal proof yet exists for CBD's effects at these targets, they represent the most probable for such investigations and should be prioritized in further studies of CBD's therapeutic mechanism of action.

Key Words: Cannabidiol · neurological disorders . mechanism of action · cannabinoid · pharmacology. 


\section{Introduction}

For millennia, mankind has associated the use of Cannabis sativa and its $\sim 100$ constituent phytocannabinoids (plant cannabinoids) with therapeutic usefulness, including for neurological disorders such as convulsions and pain [1-9]. However, such traditional use does not constitute valid evidence for the modern medical use of the plant, its extracts or components, and licensed clinical use of cannabis-based medicines remains limited to a small number of disorders such as pain in multiple sclerosis (MS), appetite stimulation in HIV/ AIDS, and cancer chemotherapy [10-12]. Moreover, the therapeutic effects of currently licensed cannabis-based treatments rely for the most part upon the pharmacological effects of the principal psychoactive component derived from the $C$. sativa plant, $\Delta^{9}$-tetrahydrocannabinol $\left(\Delta^{9}\right.$-THC) $[13]$.

More recently, the therapeutic potential of the typically second most abundant phytocannabinoid, cannabidiol (CBD), has been investigated in preclinical animal models and, together with anecdotal and often ambiguous reports of crude cannabis extracts containing high proportions of CBD exerting beneficial effects in treatment-resistant pediatric epilepsies [14], has led to formal human clinical trials of CBD in a number of epilepsies that will report results in late 2015 [15]. However, despite an extensive preclinical evidence base suggesting therapeutic utility for CBD in several neurological disorders (reviewed in this issue), a proven lack of cannabinoid type 1 receptor $\left(\mathrm{CB}_{1} \mathrm{R}\right)$-mediated psychoactivity [16], and good tolerability, the specific molecular target(s) through which CBD exerts its reported therapeutic effects remains undetermined.

Here, we summarize and assess the current evidence for CBD exerting plausible pharmacological effects via specific molecular targets (Part 1) before considering separate evidence of the extent to which these targets may be involved in mediating therapeutic effects in a variety of neurological disorders (Part 2) that were selected to complement the reviews also presented in this issue.

\section{Methods}

In order to identify molecular targets of CBD within the existing literature, a PubMed search, using filters that excluded review articles, for the term "cannabidiol" was performed. Results were then manually reviewed to determine whether or not original results describing CBD effects in molecular target specific assays were presented. Thus, only peer-reviewed, original publications that included results from assays specific to a given molecular target were included in this review.

Part 1 also considers the plausibility of a given molecular target as having the potential to play a role in CBD's therapeutic effects by virtue of potency and efficacy information where available. With regard to potency, as most studies reviewed relied upon evidence derived from preclinical animal models of disease, we selected a specific concentration beyond which effects reported by in vitro studies cannot realistically be achieved in vivo. This guideline was based upon data derived from a detailed report of CBD's plasma and brain pharmacokinetic profile following administration via a number of routes (orally and intraperitoneally) in both mouse and rat [17]. Thus, in vitro effects reported in Part 1 that require CBD concentrations $\geq 10-20 \mu \mathrm{M}$ were considered supraphysiological and so such molecular targets were not considered in Part 2.

\section{Part 1: Molecular Targets of CBD}

\section{Receptor Targets}

Our review of the current literature revealed 11 investigations of the effect of $\mathrm{CBD}$ upon 10 specific receptor targets, which account for $15 \%$ of the known molecular targets of CBD (Fig. 1, Table 1).

\section{Cannabinoid Receptors}

In contrast to $\Delta^{9}$-THC, CBD has a very low affinity and shows little agonist activity at the $\mathrm{G}$ protein-coupled endocannabinoid system (ECS) receptors, $\mathrm{CB}_{1} \mathrm{R}$ and $\mathrm{CB}_{2} \mathrm{R}$ [29]. However, despite this micromolar affinity, some of the literature reports $\mathrm{CBD}$ as having an antagonistic profile against $\mathrm{CB}_{1} \mathrm{R} / \mathrm{CB}_{2} \mathrm{R}$ agonists with a nanomolar $\mathrm{K}_{\mathrm{B}}[30]$. More recently, a statistical meta-analysis of all extant data describing direct effects of $C B D$ at $\mathrm{CB}_{1} \mathrm{R}$ and $\mathrm{CB}_{2} \mathrm{R}$ concluded that there is no direct $\mathrm{CBD}-\mathrm{CB}_{1} \mathrm{R}$ interaction that can account for the reported changes in endocannabinoid signaling [16]. Indeed, the pharmacology of CBD at cannabinoid receptors is not only complex and highly variable [31-33], but also typically occurs at supraphysiological concentrations in vitro, so rendering any contribution to behavioral effects unlikely. These clear discrepancies between in vitro and in vivo studies are a warning to pharmacologists that predicted pharmacology from molecular assay systems is not always replicated at a system level.

\section{Adenosine}

CBD not only elicits effects within the central nervous system (CNS), but also within the cardiovascular system. Adenosine receptors have been implicated in regulating coronary blood flow and oxygen consumption by cardiac muscle and are present in the brain, most notably in the forebrain $[34,35]$. CBD $(50 \mu \mathrm{g} / \mathrm{kg})$ inhibits the subsequent ventricular tachycardia following coronary artery occlusion in rats - an effect abolished by 8-cyclopentyl-1,3-dipropylxanthine, an 
Fig. 1 Pie chart showing the proportions of different molecular targets for cannabidiol described in the reviewed literature. Chart shows percentage proportions from a total of 65 targets. Targets counted were unique and not counted per literature report

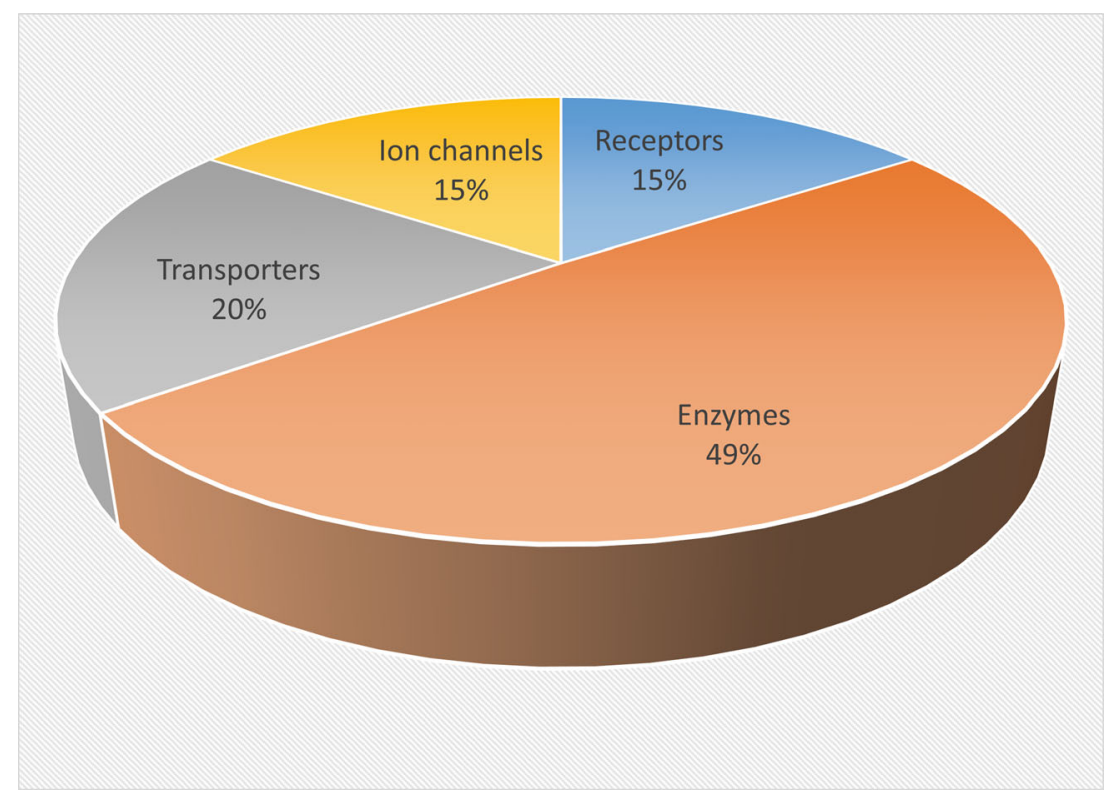

adenosine $A_{1}$ receptor antagonist (Table 1). These results demonstrate that CBD can exert an antiarrhythmic effect, possibly mediated by the adenosine $\mathrm{A}_{1}$ receptor [36]. In addition to effects on the $A_{1}$ receptor, $A_{2}$ receptor-mediated effects of CBD have also been reported and claimed to mediate antiinflammatory effects of CBD [10, 31, 37, 38]. The effects of CBD on inflammatory signaling cascades have also been examined (Table 1) [37]. Here, retinal tumor necrosis factor- $\alpha$ secretion following lipopolysaccharide injection was suppressed by CBD ( $1 \mathrm{mg} / \mathrm{kg})$, and the pharmacology of this response was further dissected using ZM 241385, an adenosine $A_{2}$ antagonist. The authors also suggested that the observed CBD effects could arise though modulation of adenosine transport (see "Transporters"). Using in vitro and in vivo models of MS demonstrated that an adenosine $\mathrm{A}_{2}$ receptormediated component of the inflammatory response was suppressed by CBD (in vivo: $5 \mathrm{mg} / \mathrm{kg}$; in vitro: $1 \mu \mathrm{M}$ ) [10]. However, it was noted that the adenosine $\mathrm{A}_{2}$-mediated response was only partially responsible for the antiinflammatory observations, again through use of the adenosine $A_{2}$ antagonist ZM241385. Studies have suggested that neuroprotective effects of CBD are mediated via adenosine $\mathrm{A}_{2}$ receptor modulation [31]. However, this has also been contested where species differences and animal developmental stages in the methodology of these conflicting studies may underlie the different conclusions drawn [38]. Therefore, a clear link between the reported neuroprotective effects of $\mathrm{CBD}$ and adenosine $\mathrm{A}_{2}$ receptors has not yet been shown.

\section{Glycine Receptors}

Another molecular target of $\mathrm{CBD}$ has been revealed by 2 comprehensive studies investigating glycine-mediated synaptic transmission $[21,22]$. Pentameric glycine ionotropic receptors (GlyR) mediate neuropathic pain and inflammation through $\mathrm{Cl}^{-}$flux where, at present, $4 \alpha$ subunit $\left(\alpha_{1-4}\right)$ isoforms and 1 isoform of the $\beta$ subunit have been described [39]. Using in vitro electrophysiological assays, CBD (1-300 $\mu \mathrm{M})$ modulated strychnine-sensitive $\alpha 1$ and $\alpha 1 \beta$ GlyR. At concentrations $>100 \mu \mathrm{M}$, direct activation of these GlyR was observed [21], although the physiological pertinence of an effect at such a high concentration remains unknown. Subsequently, it was shown that in HEK293 cells expressing $\alpha 3$ GlyRs, $1 \mu \mathrm{M}$ CBD increased glycine-induced current amplitude almost 5-fold in comparison with glycine alone (Table 1) [22]. Of interest was the observation that dehydroxyl-CBD $(1 \mu \mathrm{M})$ was more efficacious than CBD as it initiated a 9-fold increase in current amplitude. This observation led to the more recent study highlighting a role for dehydroxyl-CBD in modulating presynaptic GlyR and suggested a homomeric conformational bias for dehydroxylCBD effects [40].

\section{Opioid Receptors}

Opioid receptors $(\mathrm{ORs})$ are $\mathrm{G}_{\mathrm{i} / \mathrm{o}}$ protein-coupled receptors that bind opiates [41]. CBD $(0.1-100.0 \mu \mathrm{M})$ may serve as an allosteric modulator at $\mu$ and $\delta$ ORs (Table 1) [28]. In rat cortical membranes, disassociation of OR agonist [D-Ala ${ }^{2}, \mathrm{~N}$ $\mathrm{MePhe}^{4}$, Gly-ol]-encephalin from $\mu$ ORs was seen following the application of CBD. A similar effect was observed for $\delta$ ORs. For both receptor isoforms, half maximal inhibition was produced at approximately $10 \mu \mathrm{M}$ (Table 1 ). However, the inhibitory constant varied between subtypes $[18.4 \mu \mathrm{M}(\delta$ isoform) and 31.6 $\mu \mathrm{M}$ ( $\mu$ isoform)] [28]. 
Table 1 Receptor targets of cannabidiol

\begin{tabular}{|c|c|c|c|c|c|c|}
\hline Target & $\begin{array}{l}\text { Concentration } \\
\text { range }(\mu \mathrm{M})\end{array}$ & $\begin{array}{l}\mathrm{EC}_{50} / \mathrm{IC}_{50} \\
(\mu \mathrm{M})\end{array}$ & $\mathrm{K}_{\mathrm{i}}(\mu \mathrm{M})$ & Preparation or tissue & Assay type & Reference \\
\hline \multirow[t]{4}{*}{$\mathrm{CB}_{1}$} & $3 ; \mathrm{NSC}$ & ND & ND & A549/human & Viability & \multirow[t]{2}{*}[18]{} \\
\hline & 3 ; NSC & ND & ND & H460/human & Viability & \\
\hline & NSC & $>10$ & ND & ND & ND & [19] \\
\hline & $\mathrm{NSC}$ & $>30$ & ND & HEK293 membrane/human & $\mathrm{GTP} \gamma \mathrm{S}$ & {$[20]$} \\
\hline \multirow[t]{4}{*}{$\mathrm{CB}_{2}$} & 3 ; NSC & ND & ND & A549/human & Viability & \multirow[t]{2}{*}[18]{} \\
\hline & 3 ; NSC & ND & ND & H460/human & Viability & \\
\hline & $\mathrm{NSC}$ & $>10$ & ND & ND & ND & [19] \\
\hline & NSC & $>30$ & ND & HEK293 membrane/human & $\mathrm{GTP} \gamma \mathrm{S}$ & {$[20]$} \\
\hline \multirow{2}{*}{$\begin{array}{l}\text { Glycine receptor } \\
\alpha 1 \text { subunit }\end{array}$} & $1-300 ;(+)$ & 12.3 & ND & HEK293/ND & Patch clamp/current with glycine & \multirow[t]{4}{*}[21]{} \\
\hline & $1-300 ;(+)$ & 132.4 & ND & HEK293/ND & Patch clamp/current without glycine & \\
\hline \multirow{2}{*}{$\begin{array}{l}\text { Glycine receptor } \\
\alpha 1 \beta \text { subunit }\end{array}$} & $1-300 ;(+)$ & 18.1 & ND & HEK293/ND & Patch clamp/current with glycine & \\
\hline & $1-300 ;(+)$ & 144.3 & ND & HEK293/ND & Patch clamp/current without glycine & \\
\hline $\begin{array}{c}\text { Glycine receptor } \\
\alpha 3 \text { subunit }\end{array}$ & $0.01-50.00 ;(+)$ & $3 *$ & ND & HEK293/ND & Patch clamp/current without glycine & {$[22]$} \\
\hline \multirow[t]{2}{*}{ GPR18 } & $10^{-4}-100 ;(+)$ & 51.1 & ND & HEK293/ND & $\mathrm{p} 44 / 42$ & \multirow[t]{2}{*}[23]{} \\
\hline & & & & & MAPK activation & \\
\hline \multirow[t]{3}{*}{ GPR55 } & $10^{-3}-1 ;(-)$ & 0.45 & ND & Human osteoclasts & Rho and ERK1/2 activation & [24] \\
\hline & $10^{-3}-10^{-2} ;(-)$ & ND & ND & Colon & Contraction & {$[25]$} \\
\hline & $(-)$ & 0.445 & ND & HEK293 membrane/human & GTP $\gamma \mathrm{S}$ & {$[20]$} \\
\hline \multirow[t]{3}{*}{$5-\mathrm{HT}_{1 \mathrm{~A}}$} & $8-32 ;(-)$ & ND & ND & CHO membrane/human & {$[3 \mathrm{H}]-8-\mathrm{OH}-\mathrm{DPAT}$ ligand binding } & \multirow[t]{3}{*}[26]{} \\
\hline & $16 ;(-)$ & ND & ND & CHO membrane/human & {$[35 \mathrm{~S}]-\mathrm{GTP} \gamma \mathrm{S}$ assay } & \\
\hline & $16 ;(-)$ & ND & ND & $\mathrm{CHO} /$ human & Forskolin & \\
\hline $5-\mathrm{HT}_{2 \mathrm{~A}}$ & $8-32 ;(+)$ & ND & ND & NIH 3 T3 membrane/rat & {$[3 \mathrm{H}]-$ Ketanserin } & \\
\hline $\mathrm{nAChR} \alpha-7$ & $0.1-100.0 ;(-)$ & 11.3 & ND & Xenopus oocyte/human & Patch clamp/current/acetylcholine & {$[27]$} \\
\hline Opioid $(\delta)$ & $0.1-100.0 ;(-)^{*}$ & $10.7 *$ & 18.4 & Cerebral cortex membrane/rat & {$[3 \mathrm{H}]-\mathrm{NTI}$ binding assay } & [28] \\
\hline Opioid $(\mu)$ & $0.1-100.0 ;(-)^{*}$ & $10 *$ & 31.6 & Cerebral cortex membrane/rat & {$[3 \mathrm{H}]$-DAMGO binding assay } & \\
\hline \multirow[t]{2}{*}{$\operatorname{PPAR} \gamma$} & $3 ;(+)$ & ND & ND & A549/human & mRNA RT-PCR/Western blot & \multirow[t]{2}{*}[18]{} \\
\hline & $3 ;(+)$ & ND & ND & H460/human & mRNA RT-PCR/Western blot & \\
\hline
\end{tabular}

$\mathrm{CB}_{1}=$ cannabinoid type $1 ; \mathrm{CB}_{2}=$ cannabinoid type $2 ; \mathrm{GPR}=\mathrm{G}$ protein-coupled receptor; $5-\mathrm{HT}=$ serotonin; $\mathrm{nAchR}=$ nicotinic acetylcholine receptor; $\mathrm{PPAR}=$ peroxisome proliferator-activated receptor; $\mathrm{NSC}=$ no significant change; $\mathrm{ND}=$ not described; $\mathrm{HEK}=$ human embryonic kidney; $\mathrm{CHO}=$ Chinese hamster ovary; GTP $\gamma \mathrm{S}=$ guanosine 5'-O-[gamma-thio]triphosphate; MAPK = mitogen-activated protein kinase; ERK = extracellular regulated kinase; [3H]-3-OH-DPAT = 7-(dipropylamino)-5,6,7,8-tetrahydronaphthalen-1-ol; [3H]-NTI = naltrindole; [3H]-DAMGO = D-Ala ${ }^{2}, \mathrm{~N}-\mathrm{MePhe}{ }^{4}, \mathrm{Gly}-$ ol; RT-PCR = reverse transcription polymerase chain reaction; $(+)=$ stimulation; $(-)=$ inhibition

*Estimated from plots in cited paper

\section{Serotonin Receptors}

CBD may also act via serotonin (5-HT) receptors [26, 42-45]. The $5-\mathrm{HT}_{1 \mathrm{~A}}$ receptor is coupled to $\mathrm{G}$ protein $\mathrm{G}_{\mathrm{i} / \mathrm{o}}$, where it is thought to mediate inhibitory neurotransmission [46]. CBD binds to the $5-\mathrm{HT}_{1 \mathrm{~A}}$ receptor within a range of $8-32 \mu \mathrm{M}$ (Table 1) [26]. In cultured Chinese hamster ovary cells, CBD displaced radiolabelled 8-OH-DPAT [7-(dipropylamino)-5,6,7, 8-tetrahydronaphthalen-1-ol] from $5-\mathrm{HT}_{1 \mathrm{~A}}$ receptors. An increase in guanosine $5^{\prime} \mathrm{O}$-[gamma-thio]triphosphate binding to $\mathrm{G}_{\mathrm{i} / \mathrm{o}}$ and a fall in cyclic adenosine monophosphate was seen, which suggests that $\mathrm{CBD}$ can act as an agonist at the 5- $\mathrm{HT}_{1 \mathrm{~A}}$ receptor. In addition to $5-\mathrm{HT}_{1 \mathrm{~A}}$ agonism, the same study presented evidence for $\mathrm{CBD}$ binding to the $5-\mathrm{HT}_{2 \mathrm{~A}}$ receptor. In $\mathrm{NIH} / 3 \mathrm{~T} 3$ cells, CBD $(8-32 \mu \mathrm{M})$ served as a partial agonist of the $5-\mathrm{HT}_{2 \mathrm{~A}}$ receptor with weaker efficacy than its action at the
5- $\mathrm{HT}_{1 \mathrm{~A}}$ receptor [26]. 5-HT receptors are also implicated in autonomic control [47], and again here CBD has been shown to modulate $5-\mathrm{HT}_{1 \mathrm{~A}}$-mediated responses in vivo [42]. CBD (1$20 \mathrm{mg} / \mathrm{kg}$ i.p.) attenuated the stress response in male rats, as evidenced by cardiovascular parameters, and this attenuation was masked by co-administration of WAY-1000635, a 5$\mathrm{HT}_{1 \mathrm{~A}}$ antagonist (although with nonspecific effects at dopamine $\mathrm{D}_{4}$ receptors) [48]. Further studies examining central control of cardiovascular function have also shown CBD and 5$\mathrm{HT}_{1 \mathrm{~A}}$ interactions $[49,50]$. Further work using WAY-100635 has highlighted that $\mathrm{CBD}$ activation of $5-\mathrm{HT}_{1 \mathrm{~A}}$ receptors, localized to the dorsal periaqueductal gray, mediates reported panicolytic effects [43]. It is clear that CBD can modulate functions involving 5-HT receptor function, although to what extent such effects are direct remains unclear, particularly as several in vivo studies did not include 5-HT receptor antagonist-only 
study groups. Therefore, a clear demonstration of in vivo CBD5-HT receptor interaction is required.

\section{G Protein-coupled Receptor 55 (An Orphan G Protein-coupled Receptor)}

More recently, attention has turned to interactions between $\mathrm{CBD}$ and non-endocannabinoid $\mathrm{G}$ protein-coupled receptors (GPCRs) [23, 24, 51]. The orphan GPCR 55 (GPR55) shares structural similarities in transmembrane domains 1,2 , and 3 when compared with the cannabinoid receptors, which may indicate a binding site for cannabinoids [24, 52]. A radiolabelled synthetic analogue of $\Delta^{9}$-THC has been shown to bind GPR55 with an $\mathrm{EC}_{50}$ of $5 \mathrm{nM}$. Further studies with CBD (0.001-1.000 $\mu \mathrm{M})$ have shown an inhibitory effect on the agonist activity of CP 55,940 at GPR55, with an $\mathrm{IC}_{50}$ of $445 \mathrm{nM}$ [24]. Functional consequences of this inhibition have been demonstrated in rat hippocampal preparations [51]. Here, CBD $(1 \mu \mathrm{M})$ suppressed physiological activation of the GPR55 receptors, which restricted excitatory output from pyramidal cells. While the pharmacology and localization of GPR55 merits further investigation [20, 53], CBD has demonstrable antagonistic effects within rat brain with clear physiological relevance.

\section{Nicotinic Acetylcholine Receptor}

Evidence that CBD modulates nicotinic acetylcholine receptor (nAchRs) function comes from a study by Mahgoub et al. [27]. Electrophysiological recordings from Xenopus oocytes expressing the $\alpha-7-\mathrm{nAChR}$ reveal a concentration-dependent inhibition in the presence of CBD $(0.1-100.0 \mu \mathrm{M}$; Table 1). Complementary biochemical evidence highlighted a noncompetitive binding to the $\alpha-7-n A C h R$. Furthermore, CBD (1-30 $\mu \mathrm{M})$ inhibited acetylcholine-induced ion currents recorded in rat hippocampal slices $\left(\mathrm{IC}_{50}=12.7 \mu \mathrm{M}\right)[27]$.

\section{Peroxisome Proliferator-activated Receptors}

The peroxisome proliferator-activated receptor (PPAR) $\gamma$, otherwise known as the glitazone receptor, is thought to be responsible for lipid storage and glucose metabolism [18], and some anticancer effects of CBD are thought to by mediated through interaction with PPAR $\gamma$. In human A549 and A460 cancer cell lines, a time-dependent increase in PPAR $\gamma$ mRNA was observed following the application of CBD $(1-3 \mu \mathrm{M})$. CBD has also been shown to inhibit tumor cell viability; cell death assays revealed $\mathrm{IC}_{50}$ values of $3.47 \mu \mathrm{M}$ (A549) and $2.80 \mu \mathrm{M}$ (A460). A complete loss of tumor cell viability was observed at $8 \mu \mathrm{M}(\mathrm{A} 549)$ and $7 \mu \mathrm{M}(\mathrm{A} 460)$ [18]. Interestingly, these effects on tumor cells were not prevented by pharmacological tools acting at $\mathrm{CB}_{1} \mathrm{R}, \mathrm{CB}_{2} \mathrm{R}$, or transient receptor potential (TRP) vanilloid-type 1 (TRPV1). These results do not confirm a direct effect of CBD upon PPAR $\gamma$ but the extant data warrants its inclusion for completeness. Furthermore, CBD was shown to displace a fluorescent ligand of PPAR $\gamma$ (Fluormone PPAR Green, Life Technologies, Paisley, UK) at a relatively low $\mathrm{IC}_{50}(5 \mu \mathrm{M})$ in a fluorescence polarization assay, indicating that $\mathrm{CBD}$ may bind to this protein [54]. In addition, CBD may be directly involved in PPAR $\gamma$ activation as $10 \mu \mathrm{M}$ CBD stimulates activity of the luciferase reporter gene in HEK293 cells transiently overexpressing retinoid X receptor and PPAR $\gamma$ [54].

\section{Enzyme Targets}

Our review of the current literature revealed 19 investigations of the effect of CBD upon 32 specific enzyme targets, which accounts for $49 \%$ of the known molecular targets of CBD (Fig. 1).

\section{Enzymes Involved in Xenobiotic Metabolism}

\section{Cytochrome P450}

As would be expected for a xenobiotic, CBD modulates several cytochrome P450 (CYP450) enzymes. Although early work did not show any statistically significant effect of CBD upon CYP450 function [55], more recent studies (see below) have reported several CYP450s as potential molecular targets. The CYP450 enzyme system includes P450 and its nicotinamide adenine dinucleotide (phosphate) oxidase-linked reductase and catalyzes a monoxygenation reaction. In eukaryotes, it is mainly found in the endoplasmic reticulum and mitochondria where it maintains homeostatic control of lipophilic endogenous compounds and the detoxification of lipophilic xenobiotic compounds by oxidation, making them more water soluble, and is thus the main component of phase 1 metabolism. It is highly diverse, with many different isoforms [56].

CBD inhibits human recombinant CYP2C19 using a mixed inhibition mechanism $(\mathrm{Ki}=0.793 \mu \mathrm{M})$ [57]. Additionally, CBD is a potent inhibitor of this enzyme using either high-affinity substrates such as omeprazole $\left(\mathrm{IC}_{50}=1.55\right.$ $\mu \mathrm{M})$ or 2-O-methylfluorescein $\left(\mathrm{IC}_{50}=1.79 \mu \mathrm{M}\right)$, or a lowaffinity substrate, $(\mathrm{S})$-mephenytoin $\left(\mathrm{IC}_{50}=2.51 \mu \mathrm{M}\right)$, to activate the reaction. Irrespective of substrate, CBD fully inhibits the reaction at $10 \mu \mathrm{M}$, indicating that it is a potent inhibitor. It is unclear whether this is involved in the therapeutic effect of CBD in CNS disorders as evidence of CYP2C19 expression in brain remains conflicted $[58,59]$. Two other CYPs, CYP2C9 and CYP2D6, are also potential targets for CBD as CBD also completely inhibits their function at $10 \mu \mathrm{M}[60$, 61]. However, CBD exerts a more potent effect upon CYP2C9 $\left(\mathrm{IC}_{50}=2.7 \mu \mathrm{M}\right)$ than CYP2D6 $\left(\mathrm{IC}_{50}=6.01-6.52\right.$ $\mu \mathrm{M})$. An additional study of the CYP1 family revealed that $\mathrm{CBD}$ acts as a more potent inhibitor of CYP1A $1\left(\mathrm{IC}_{50}=0.537\right.$ 
$\mu \mathrm{M})$ than CYP1A2 $\left(\mathrm{IC}_{50} \sim 3.5 \mu \mathrm{M}\right)$ and CYP1B1 $\left(\mathrm{IC}_{50}\right.$ $\sim 5 \mu \mathrm{M})$ [62]. With regard to potency, $90 \%$ of CYP1A1's activity was inhibited by $2.5 \mu \mathrm{M} \mathrm{CBD}$, while $10 \mu \mathrm{M}$ CBD inhibited approximately $65 \%$ and $75 \%$ of CYP1A2 and CYP1B1 activity, respectively.

Finally, it has been reported that CBD may inhibit members of the CYP3 family [63]. Although, CYP3A4, CYP3A5, and CYP3A7 have been identified as molecular targets for CBD (Table 2), it appears that the compound is a more potent inhibitor of CYP3A5 $\left(\mathrm{IC}_{50}=1.65 \mu \mathrm{M}\right)$ compared with CYP3A4 $\left(\mathrm{IC}_{50}=11.7 \mu \mathrm{M}\right)$ and CYP3A7 $\left(\mathrm{IC}_{50}=24.7 \mu \mathrm{M}\right)$. More importantly, around $90 \%$ of CYP3A5's activity was abolished by $10 \mu \mathrm{M}$ CBD, whereas CYP3A4 and CYP3A7 required up to $50 \mu \mathrm{M}$ - a physiologically implausible concentration [17]: CBD to achieve $~ 90$ and $72 \%$ inhibition, respectively. The mode of inhibition determined in this study was competitive for CYP3A4 and CYP3A5 but mixed for CYP3A7.

\section{Other Enzymes Involved in Xenobiotic Metabolism}

The involvement of CYP450 is only part of the metabolism of CBD [77], which has been linked to many other enzymes involved in the control of redox. Oxidation of xenobiotics can potentially produce highly reactive intermediates and is why phase I and II metabolism is integrated with electrophilic sensors [e.g., the nuclear factor (erythroid-derived 2)-like 2 (NRF2)-Kelch-like ECH-associated protein 1 pathway), which can upregulate cytoprotective genes and pathways [78]. In this regard, CBD can activate NRF2 [79].

Several enzymes implicated in the regulation of redox have been identified as potential molecular target of CBD [55]. Here, $100 \mu \mathrm{M}$ CBD applied to mouse hepatic 105,000 g supernatant reduced superoxide dismutase and catalase activity by approximately $76 \%$ and $24 \%$, respectively, and nicotinamide adenine dinucleotide (NAD)- and NAD phosphatedependent $\mathrm{NAD}(\mathrm{P}) \mathrm{H}$ quinone reductase by $80 \%$ and $81 \%$, respectively, when compared with controls. Moreover, CBD, at the same concentration, also significantly stimulated glutathione peroxidase and glutathione reductase by $24 \%$ and $40 \%$, respectively. However, it is notable that the concentration of CBD used in this study was far in excess of that which can be achieved physiologically [17].

\section{Enzymes Involve in Cholesterol Metabolism}

Several studies have reported the action of CBD upon enzymes involved in cholesterol metabolism. Although some of the efficacious concentrations reported are achievable in vivo, several are not and so can be excluded from consideration.

Acyl-cholesterol acyltransferases (ACATs) catalyze the formation of cholesterylester from long-chain fatty acyl- coenzme A (CoA) and cholesterol. CBD may antagonize the overall activity of ACAT (without distinguishing the individual activity of each subtype) in human fibroblast cells [64]. The potency of CBD on cholesteryl ester formation in the presence of $0.1 \mathrm{mM}\left[{ }^{14} \mathrm{C}\right]$-oleate-CoA and $5 \mu \mathrm{g} / \mathrm{ml} 25-\mathrm{OH}-$ cholesterol could be estimated to $<10 \mu \mathrm{M}$. Furthermore, $30 \mu \mathrm{M} \mathrm{CBD}$ appears to reduce $90 \%$ of the formation of this product.

The synthesis of mevalonate from 3-hydroxy-3methylglutaryl-CoA is catalyzed by 3-hydroxy-3methylglutaryl-CoA reductase, which has been shown to be stimulated by $\mathrm{CBD}$ [64]. Although an $\mathrm{EC}_{50}$ for $\mathrm{CBD}$ was not determined, the in vitro production of mevalonate was increased 4.5-fold in human fibroblasts exposed to $30 \mu \mathrm{M}$ $\mathrm{CBD}$ when compared with cells exposed to $1 \mu \mathrm{M}$ CBD. The exact mechanism by which CBD exerts its stimulatory effect on the enzyme is still unclear.

CBD has also been reported to inhibit progesterone $17 \alpha$ hydroxylase, testosterone $6 \alpha$-hydroxylase, and testosterone $16 \beta$-hydroxylase [75]. However, CBD exhibits only weak efficacy as $10 \mathrm{mM}$ CBD is required to inhibit $\sim 20 \%, 49 \%$, and $67 \%$ of progesterone $17 \alpha$-hydroxylase, testosterone $6 \alpha$ hydroxylase, and testosterone $16 \beta$-hydroxylase, respectively. Thus, it is unrealistic to propose that these enzymes are meaningfully involved in the therapeutic effect of CBD in neurological disorders.

\section{Effects on Enzymes Controlling Ceramide}

Ceramide is a secondary messenger with a range of effects, including induction of differentiation to apoptosis. It can be viewed as part of a stress signaling pathway and can be produced either via sphingomyelinase-dependent hydrolysis or by de novo synthesis. It also plays an important role in membrane rafts and the control of ion channels [80,81].

Over 3 decades ago, CBD was shown to activate the breakdown of sphingomyelin in fibroblasts taken from a patient with Niemen-Pick disease [76]. Prior to CBD treatment, these cells exhibited $<3 \%$ normal sphingomyelinase activity [82]. Although no assay was performed that showed a direct effect of CBD on sphingomyelinase, the authors demonstrated that $16 \mu \mathrm{M}$ CBD reduced sphingomyelin levels by $77 \%$. In contrast, when the same in vitro assay was performed on normal fibroblasts (WI-38 human lung fibroblasts) CBD exerted no statistically significant effect on sphingomyelin hydrolysis. Furthermore, the antitumor effect of CBD has been shown to be independent on the production of ceramide in human glioma cells (but was associated with a fall in mitochondrial potential; see below) [83] and thus it remains unclear as to whether or not CBD acts directly on the ceramide pathway. 


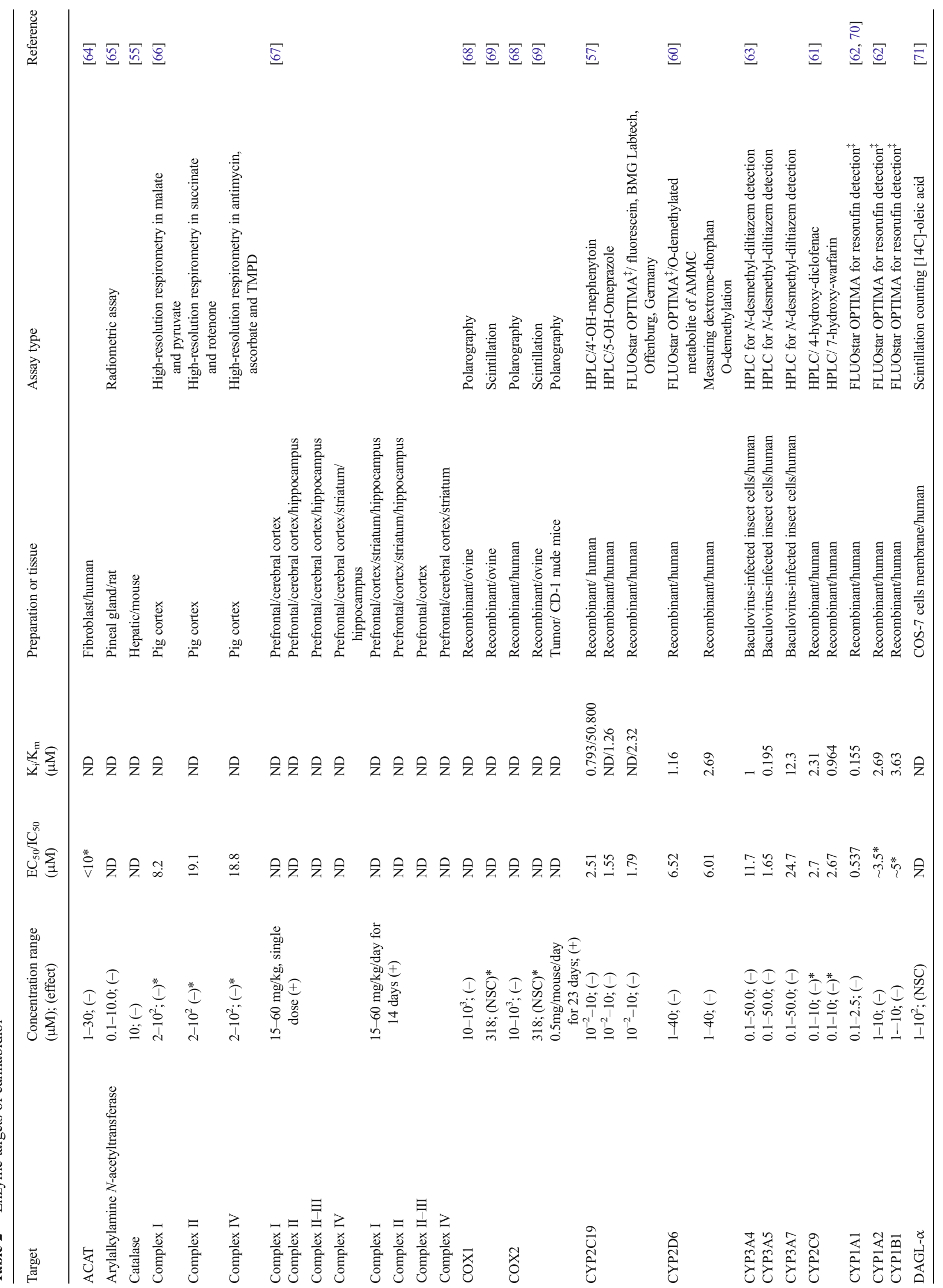




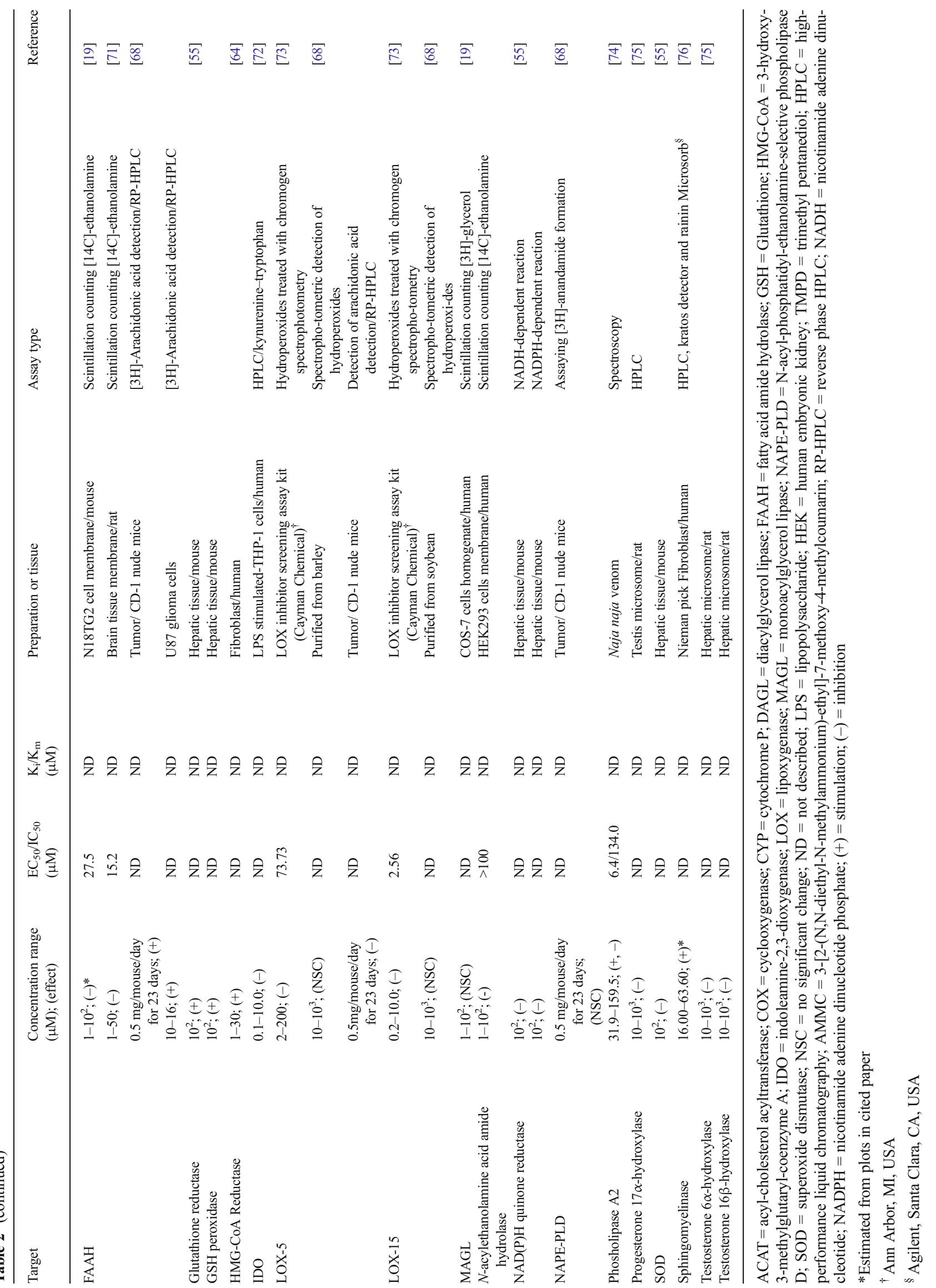




\section{Electron Transport Chain}

The mitochondrial electron transport chain (ETC) comprises a group of 4 enzymatic complexes (known as, complex I, II, III, and IV) involved in mitochondrial bioenergetics. Recent studies suggest that CBD may alter mitochondrial bioenergetics via modulation of ETC activity [67]. Moreover, mitochondrial bioenergetics may also be modified by $\mathrm{CBD}$ via interaction with mitochondrial voltage-dependent anion channel 1 (VDAC1; see "Ion Channels") [84], which may affect the production of adenosine triphosphate (ATP). VDAC1 is involved in the transport of ions (e.g., calcium) and multiple metabolites, including adenosine diphosphate [85], the substrate of ATP.

There are still some discrepancies surrounding the nature of CBD's action on the complexes comprising the ETC. Acute or chronic in vivo administration (Table 2) of CBD $(60 \mathrm{mg} / \mathrm{kg}$, i.p.) increased the activity of complex I, II/III, and IV in tissue obtained from cerebral and the prefrontal cortex in rat [67], while in vitro application of $\mathrm{CBD}$ to isolated mitochondria from pig brain antagonized the activity of complex I $\left(\mathrm{IC}_{50}=\right.$ $8.2 \mu \mathrm{M})$, II $\left(\mathrm{IC}_{50}=19.2 \mu \mathrm{M}\right)$, and IV $\left(\mathrm{IC}_{50}=18.8 \mu \mathrm{M}\right)[66]$; apart from complex I, the $\mathrm{IC}_{50}$ values presented are inconsistent with the concentrations likely to be achieved by the in vivo study to which we have compared [17]. Moreover, this latter study determined that CBD exerted a greater effect on complexes I and II than on complex IV as $100 \mu \mathrm{M}$ CBD fully inhibited complexes I and II, while complex IV retained $\sim 75 \%$ activity. These results were confirmed by a recent in vitro study which showed that CBD inhibits directly complexes I, II/III, and IV only at higher concentrations $(50 \mu \mathrm{M})$ [86].

In summary, it would seem that CBD acts differently on mitochondrial complexes depending on the route of administration. While the number of studies in this area remains small, they appear to suggest that CBD effects on ETC complexes may involve indirect mechanisms (e.g., increase ETC complex expression or mitochondrial biogenesis) that ultimately result in the bioenergetic increases reported by Valvassori et al. [67], although a direct interaction between CBD and complex I may inhibit this enzyme [66].

\section{Arylalkylamine N-Acetyltransferase}

Arylalkylamine $\mathrm{N}$-acetyltransferase (AANAT) plays a role in melatonin synthesis, which controls circadian rhythm, orchestrated by the pineal gland, although melatonin performs other functions, including control of neuroexcitation, immune modulation, and protection against oxidative stress [87-89]. The effect of CBD on norepinephrine-induced activation of AANAT in the rat pineal gland and in cell-free lysates has been studied where $10 \mu \mathrm{M}$ CBD significantly attenuated norepinephrine induction of melatonin synthesis by $35 \%$ compared with controls in isolated pineal glands, while $1 \mu \mathrm{M}$ inhibited AANAT activity by $35 \%$ [65]. This effect was shown to be independent of $\mathrm{CB}_{1} \mathrm{R}$ or $\mathrm{CB}_{2} \mathrm{R}$ and due to direct AANAT inhibition demonstrated using cell-free lysates of the pineal gland where $10 \mu \mathrm{M}$ CBD inhibited AANAT by $40 \%[65]$.

\section{Effect of CBD on Phospholipases}

Phospholipases are responsible for the breakdown of complex lipids and play a key role in lipid signaling. In particular, phospholipase A2 (PLA2) may play a key role in brain inflammation and thus neurodegeneration [90]. CBD has been reported to act upon Naja naja venom PLA2, while it has no effect on $N$-acylphosphatidyl-ethanolamines-hydrolyzing phospholipase D, monoacylglycerol lipase, or diacylglycerol lipase- $\alpha$ (Table 2). Using an in vitro assay, the effect of CBD upon $N$. naja venom $\mathrm{PLA}_{2}$ was reportedly biphasic where low concentration $\mathrm{CBD}$ stimulated activity $\left(\mathrm{EC}_{50}=6.4 \mu \mathrm{M}\right.$; maximum induction $=262 \%$ induction at $39.1 \mu \mathrm{M}$ ), while at higher concentrations, activity was inhibited $\left(\mathrm{IC}_{50}=134 \mu \mathrm{M}\right.$; maximum inhibition $\sim 60 \%$ inhibition at $159.5 \mu \mathrm{M}$ ) [74]. While the reported $\mathrm{EC}_{50}$ is physiologically achievable in vivo, it is unclear whether CBD exerts the same effects upon mammalian PLA2s as they are likely to be structurally and functionally different from $N$. naja venom PLA2 [91].

While studying the effect of CBD on phospholipases involved in regulation of endocannabinoids, repeated administration of CBD $(0.5 \mathrm{mg} /$ mouse $)$ in female CD-1 nude mice for 23 days was shown not to change the in vivo activity of $N$ acylphosphatidyl-ethanolamine-phospholipase D. Similarly, the same authors showed that CBD does not act upon the human monoacylglycerol lipase and diacylglycerol lipase- $\alpha$ expressed in COS-7 cells [68].

\section{Effect on Fatty Acid Amide Hydrolase}

Fatty acid amide hydrolase (FAAH) is an enzyme involved in the catabolism of fatty acid amides (e.g., the endocannabinoid, anandamide) and reports of CBD effects at this target are conflicted throughout the literature. Two studies that investigated the effects of CBD on membrane extracted FAAH in vitro reported different $\mathrm{IC}_{50}$ values $(27.5 \mu \mathrm{M}$ and 15.2 $\mu \mathrm{M}$, respectively) $[19,71]$; marginal differences that could conceivably arise via tissue and/or species differences (Table 2). These results suggest that higher CBD concentrations may exert inhibitory effects on FAAH. In contrast, an in vitro study in U87 cells suggested that $16 \mu \mathrm{M}$ CBD stimulated FAAH by $\sim 2$-fold when compared with untreated cells [68]. Furthermore, the same study found that mice treated with $0.5 \mathrm{mg}$ CBD peritumorally for 23 days exhibited increased FAAH activity via a possible post-translational modification as the protein content did not differ from untreated mice [68]. 
Consequently, based on the limited and conflicting evidence, it appears that CBD's effects upon FAAH may depend upon the physiological environment in which it is studied as cellular or systemic systems reveal CBD-induced FAAH activation, while membrane extract assays reveal $\mathrm{CBD}$-induced inhibition. Such an environment-dependent effect suggests that more than one mechanism may be involved - short-term direct effects and longer-term, post-translational modifications are probably both at play [68]. It is also notable that reported effects upon FAAH only occur at relatively high micromolar concentrations.

\section{Cyclooxygenases and Lipoxygenases}

Cyclooxygenases (COXs) and lipoxygenases (LOXs) metabolize free arachidonic acid into 2-series prostaglandins and 4series leukotrienes, respectively [92]. Here, COX1 and COX2 activity was partially inhibited (50\% and $40 \%$, respectively) by $\mathrm{CBD}$ at very high concentrations $(500 \mu \mathrm{M})$ in an in vitro assay (Table 2) [68]. Although $\mathrm{IC}_{50}$ values were not determined in this study, inhibitory effects of CBD were reported from $50 \mu \mathrm{M}$ and $100 \mu \mathrm{M}$ for COX1 and COX2, respectively - concentrations hard to achieve in vivo [17]. Conversely, a different study showed that $318 \mu \mathrm{M}$ CBD had no effect upon the in vitro activities of COX1 and COX2 (Table 2) [69], while in vivo administration of $\mathrm{CBD}$ had no effect upon COX2 activity in tumor tissue [68] (Table 2). However, a further study suggested that CBD may modulate COX2 activity by stimulating transcription and/or translation in some subtypes of cells [18]. While the concentrations described above are unlikely to be physiologically achievable, a more recent study suggested that $10 \mu \mathrm{M}$ CBD increased arterial vasorelaxation in diabetic Zucker rats, which was associated with COX1 and COX2 stimulation via an allosteric mechanism [93].

CBD has also been reported to act as an inhibitor of 15LOX and 5-LOX. However, CBD exerts a more potent effect on 15-LOX $\left(\mathrm{IC}_{50}=2.56 \mu \mathrm{M}\right)$ than 5-LOX $\left(\mathrm{IC}_{50}=73.73 \mu \mathrm{M}\right)$ in vitro [73]. Furthermore, $200 \mu \mathrm{M} \mathrm{CBD}$ cannot fully abolish 5-LOX activity, while 15-LOX activity can be fully blocked by $10 \mu \mathrm{M} \mathrm{CBD}$, indicating that the efficacy of CBD is higher upon 15-LOX. However, these results are in contradiction with previous work which showed that CBD exerted no effect upon 5- and 15-LOX in vitro, despite in vivo administration inhibiting 5-LOX activity in tumor tissue [68].

\section{Indoleamine-2,3-dioxygenase}

Indolamine-2,3-dioxygenase (IDO) is activated by inflammation, in particular by interferon- $\gamma$ and is thought to be involved in inflammatory-associated depression (cytokine-induced sickness behavior). Its overactivation may be important in neurodegeneration as it can result in oxidative stress. It catalyzes the degradation of ring-containing compounds, in particular tryptophan to kynurenine [94].

CBD exerts biphasic effects on the kynuenine/tryptophan ratio in human monocytic cells stimulated with concavlin A or phytohemagglutinin (PHA), suggesting modulation of IDO where $0.03-0.3 \mu \mathrm{M}$ CBD stimulated them, whereas the $\mathrm{IC}_{50}$ was about $8.9 \mu \mathrm{M}$. The highest concentration tested $(16 \mu \mathrm{M})$ almost completely inhibited IDO mRNA expression induced by PHA. CBD was also shown to inhibit LPS stimulation of THP-1 cell IDO activity $\left(\mathrm{IC}_{50}=0.9 \mu \mathrm{M}\right)$. Given the bidirectional nature of CBD effects upon IDO, it is most likely that CBD concentrations typically achieved in in vivo studies in animal models of disease will inhibit IDO [17].

\section{Ion Channel Targets}

The available literature revealed 10 investigations of the effect of CBD upon 10 specific ion channel targets, which accounted for $15 \%$ of the known molecular targets of CBD (Fig. 1).

\section{TRP Channels}

CBD has been reported to act as an agonist at human TRPV1 channel expressed in HEK293 cells when assessed using a fluorescence-based, high-throughput assay with an efficacy of $70 \%$ that of a saturating concentration of the positive control, ionomycin $(4 \mu \mathrm{M})$ (Table 3$)$ [19]. TRP channels are present in the plasma membrane of a variety of cells in many tissues and act as ligand-gated, nonselective cation channels permeable to sodium, calcium, and magnesium ions [102]. Here, CBD-induced increases in intracellular calcium $\left(\left[\mathrm{Ca}^{2+}\right]_{\mathrm{i}}\right)$ were reportedly abolished by the TRPV1 antagonist capsazepine $(10 \mu \mathrm{M})$, suggesting a TRPV1-specific effect of CBD. The authors also asserted that CBD did not affect $\left[\mathrm{Ca}^{2+}\right]_{\mathrm{i}}$ in non-TRPV1-expressing HEK293 cells but did not present supporting data. Notably, other molecular targets of CBD are present in HEK293 cells (e.g., VDAC1; see Tables 1, 2, 3 and 4) but their expression on intracellular membranes is likely to prevent CBD-mediated effects from being identified by an assay such as this. This group used the same approach in a later study that examined anticancer effects of CBD [99], where CBD effects at human TRPV1 expressed in HEK293 cells were again assessed and reported in the same way as above. While specific $\mathrm{EC}_{50}$ and efficacy results for were not formally presented, an estimate from the concentration-response curves published in suggests that CBD was both less efficacious $(\sim 50 \%$ vs $70 \%)$ and less potent $(\sim 6.3 \mu \mathrm{M} v s 3.5$ $\mu \mathrm{M})$ than previously reported [99]. The same group used the same approach to assess CBD effects at human TRPV1 expressed in HEK293 cells for a third and final time [71]. Again, some disparity between the results presented and those previously published was evident as CBD's efficacy was consistent with that reported by Ligresti et al. [99] but not that 
Table 3 Ion channel targets of cannabidiol

\begin{tabular}{|c|c|c|c|c|c|c|}
\hline Target & $\begin{array}{l}\text { Concentration } \\
\text { range }(\mu \mathrm{M})\end{array}$ & $\begin{array}{l}\mathrm{EC}_{50} / \mathrm{IC}_{50} \\
(\mu \mathrm{M})\end{array}$ & $\mathrm{K}_{\mathrm{i}}(\mu \mathrm{M})$ & Preparation or tissue & Assay type & Reference \\
\hline Cav3.1 T-type & $10^{-2}-10 ;(-)$ & 0.82 & ND & HEK293 cells/human & \multirow[t]{3}{*}{ Patch clamp/ current clamp } & \multirow[t]{3}{*}[95]{} \\
\hline Cav3.2 T-type & $10^{-2}-10 ;(-)$ & 0.78 & ND & HEK293 cells/Hhuman & & \\
\hline Cav3.3 T-type & $10^{-2}-30 ;(-)$ & 3.7 & ND & HEK293 cells/human & & \\
\hline \multirow[t]{4}{*}{ TRPA1 } & ND-100; (-) & 81.4 & ND & HEK 293 cells/rat & Calcium mobilization assays & [96] \\
\hline & $10^{-3}-10 ;(-)^{*}$ & 0.096 & ND & HEK 293 cells/rat & Calcium assay/Fluo4-AM & [97] \\
\hline & $3-30 ;(+)$ & ND & ND & HEK 293 cells/rat & Patch clamp/current & [98] \\
\hline & $10^{-3} *-25 ;(-)$ & 0.11 & ND & HEK 293 cells/rat & Calcium assay/Fluo4-AM & [71] \\
\hline \multirow[t]{2}{*}{ TRPM8 } & $10^{-3}-10 ;(-)^{*}$ & 0.14 & ND & HEK 293 cells/rat & \multirow[t]{2}{*}{ Calcium assay/Fluo4-AM } & [97] \\
\hline & $10^{-3}-25^{*} ;(-)$ & 0.06 & ND & HEK 293 cells/rat & & [71] \\
\hline \multirow[t]{7}{*}{ TRPV1 } & $0.1-10.0 ;(+)$ & 3.5 & ND & HEK 293 cells/human & Calcium assay/Fluo-3 & [19] \\
\hline & $10^{-3}-25 ;(+)^{*}$ & 1 & ND & HEK 293 cells/human & Calcium assay/Fluo4-AM & [71] \\
\hline & ND-100; (NSC) & ND & ND & HEK 293 cells/rat & Calcium mobilization assays & {$[96]$} \\
\hline & $3-30 ;(+)$ & ND & ND & HEK 293 cells/rat & Patch clamp/current & [98] \\
\hline & $3 ;(\mathrm{NSC})$ & ND & ND & A549/human & Viability & \multirow[t]{2}{*}[18]{} \\
\hline & $3 ;(\mathrm{NSC})$ & ND & ND & A549/human & DNA fragmentation & \\
\hline & $10^{-3}-10 ;(+)^{*}$ & $0.7^{*}$ & ND & MDA-MB-231 cells & Calcium assay/Fluo4 & [99] \\
\hline \multirow[t]{7}{*}{ TRPV2 } & $0.05-10^{3} ;(+)^{*}$ & 31.7 & ND & HEK 293 cells/human & Calcium mobilization assay & [96] \\
\hline & $0.1-200.0 ;(+)^{*}$ & 22.2 & ND & U87MG glioma cells/rat & Calcium mobilization assay & {$[100]$} \\
\hline & $10^{-3}-25^{*} ;(+)$ & 1.25 & ND & HEK 293 cells/rat & Calcium assay/Fluo4-AM & [71] \\
\hline & $0.05-500.00 ;(+)^{*}$ & 3.7 & ND & HEK 293 cells/rat & Calcium mobilization assay & {$[96]$} \\
\hline & $3-30 ;(+)$ & ND & ND & HEK293 cells/rat & Patch clamp/current & [98] \\
\hline & $3 ;(\mathrm{NSC})$ & ND & ND & H460/human & Viability & \multirow[t]{2}{*}[18]{} \\
\hline & $3 ;(\mathrm{NSC})$ & ND & ND & H460/human & DNA fragmentation & \\
\hline TRPV3 & $10^{-1}-10^{3} ;(+)^{*}$ & 3.7 & ND & HEK 293 cells/rat & Calcium assay/Fluo4-AM & {$[101]$} \\
\hline TRPV4 & $10^{-2}-10^{2} ;(+)^{*}$ & 0.8 & ND & HEK 293 cells/rat & Calcium assay/Fluo4-AM & \\
\hline \multirow[t]{2}{*}{ VDAC1 } & $20 ;(-)$ & ND & ND & $\begin{array}{l}\text { Liver VDAC1 channel in } \\
\text { planar lipid bilayer/sheep }\end{array}$ & $\begin{array}{l}\text { Bilayer Clamp BC-525B } \\
\text { amplifier/current }\end{array}$ & \multirow[t]{2}{*}[84]{} \\
\hline & $0.1-75.0 ;(+)^{*}$ & ND & $\mathrm{Kd} ; 11.2$ & $\begin{array}{l}\text { Liver VDAC1 channel in } \\
\text { planar lipid bilayer/sheep }\end{array}$ & $\begin{array}{l}\text { Thermophoretic analysis/ } \\
\text { CBD-VDAC1 interaction }\end{array}$ & \\
\hline
\end{tabular}

$\mathrm{TRP}=$ transient receptor potential; TRPA1 $=$ TRP ankyrin type 1 ; TRPM8 $=$ TRP subfamily M; TRPV1 $=$ TRP vanilloid-type 1 ; VDAC $=$ voltage-dependent anion channel; $\mathrm{NSC}=$ no significant change; $\mathrm{ND}=$ not described; HEK = human embryonic kidney; $\mathrm{CBD}=$ cannabidiol; $(+)=$ stimulation; $(-)$ : inhibition *Estimated from plots in cited paper

reported by Bisogno et al. [19]; however, potency differed from both preceding papers $\left(\mathrm{EC}_{50}: 1.0 \mu \mathrm{M} v s 6.3 \mu \mathrm{M}\right.$ ([71] estimated from Ligresti et al. [99] vs $3.5 \mu \mathrm{M}$ [19]). Taken together, these results suggest that $\mathrm{CBD}$ can submaximally activate TRPV1 receptors, although the potency of CBD's effects remains less well defined. Analysis of the above results yields an approximate mean $\mathrm{EC}_{50}$ value of $3.5 \mu \mathrm{M}$ with an SEM of $1.5 \mu \mathrm{M}$, which suggests that the $95 \%$ confidence interval is greater than that values measured and could be a consequence of variability in TRPV1 in the expression systems used (V. DiMarzo, personal communication) [110].

In contrast to the above studies, comparable fluorescencebased $\mathrm{Ca}^{2+}$ imaging in HEK293 cells expressing rat TRPV1 receptors revealed that CBD $(100 \mu \mathrm{M})$ produced a response that was only $21 \%$ of that produced by the positive control, capsaicin $(500 \mathrm{nM})$, which was insufficient to determine reliably an $\mathrm{EC}_{50}$ value [96]. Furthermore, a recent study used patch clamp techniques to assess the effect of CBD (3-30 $\mu \mathrm{M})$ on the bidirectional current recorded in HEK293 cells overexpressing rat TRPV1 receptors that can be evoked by application of the TRPV1 agonist, capsaicin $(1-10 \mu \mathrm{M})$ [98]. Although a complete concentration-response relationship for CBD was not determined, detectable currents were evoked by 10 and $30 \mu \mathrm{M}$ CBD but not by $3 \mu \mathrm{M}$. While species-specific differences in TRPV1 responsiveness could account for efficacy and potency differences in the preceding studies, the use of rat TRPV1 here and by Qin et al. [96] justifies the target's consideration. It is notable that the highest CBD concentration $(30 \mu \mathrm{M})$ studied by Iannotti et al. [98] elicited a peak response of $\sim 30 \%$ of that produced by capsaicin (c.f., 21\%). While it remains unknown whether the response to $30 \mu \mathrm{M}$ CBD represents a saturating response, it is notable that $\mathrm{CBD}$ concentrations $>20 \mu \mathrm{M}$ are 
Table 4 Transporter targets of cannabidiol

\begin{tabular}{|c|c|c|c|c|c|c|}
\hline Target & $\begin{array}{l}\text { Concentration } \\
\text { range }(\mu \mathrm{M}) \text {; } \\
\text { (effect) }\end{array}$ & $\begin{array}{l}\mathrm{EC}_{50} / \mathrm{IC}_{50} \\
(\mu \mathrm{M})\end{array}$ & $\begin{array}{l}\mathrm{K}_{\mathrm{i}} \\
(\mu \mathrm{M})\end{array}$ & Preparation or tissue & Assay type & Reference \\
\hline $\mathrm{ABCC} 1$ & $0.08-50.00 ;(-)$ & 5.5 & ND & \multirow[t]{2}{*}{ SF9/ human } & $\begin{array}{l}\text { ATPase } / N \text {-ethyl-maleimide- } \\
\text { glutathione }\end{array}$ & [103] \\
\hline ABCG2 & $0.08-50.00 ;(-)$ & 7.3 & ND & & ATPase/ sulfasalazine & [104] \\
\hline Adenosine uptake & $10^{-3}-10^{2} ;(-)$ & 3.5 & ND & Striatal tissue synaptosome/rat & $\begin{array}{l}\text { Dual-label counting } \\
{[3 \mathrm{H}] \text {-adenosine }}\end{array}$ & [105] \\
\hline Adenosine uptake & $10^{-2}-1 ;(-)$ & 0.12 & ND & EOC-20 microglia/ mouse & $\begin{array}{l}\text { Scintillation counting/ } \\
{[3 \mathrm{H}] \text {-adenosine }}\end{array}$ & [106] \\
\hline \multirow{2}{*}{$\begin{array}{l}\text { Anandamide } \\
\text { uptake (AMT) }\end{array}$} & $5-50 ;(-)^{*}$ & 22 & ND & \multirow[t]{2}{*}{$\mathrm{RBL}-2 \mathrm{H} 3$ cells/rat } & \multirow{2}{*}{$\begin{array}{l}\text { Scintillation counting/ } \\
\text { [14C]-anandamide }\end{array}$} & [19] \\
\hline & $1-25 ;(-)$ & 25.3 & ND & & & {$[71]$} \\
\hline \multirow[t]{2}{*}{ Dopamine uptake } & $0.5-100.0 ;(-)^{*}$ & 16.2 & ND & Striatal tissue synaptosome/ rat & $\begin{array}{l}\text { Dual-label counting/ } \\
{[3 \mathrm{H}] \text {-dopamine }}\end{array}$ & \multirow[t]{3}{*}{ [105] } \\
\hline & $0.005-10.000 ;(-)^{*}$ & ND & ND & $\begin{array}{l}\text { Hippocampus/corpus striatum/ } \\
\text { rat }\end{array}$ & {$[3 \mathrm{H}]$-dopamine } & \\
\hline Glutamate uptake & $1-10^{2} ;(-)$ & 43.8 & ND & Striatal tissue synaptosome/rat & $\begin{array}{l}\text { Dual-label counting/ } \\
{[3 \mathrm{H}] \text {-glutamate }}\end{array}$ & \\
\hline $\mathrm{Mg}^{2+}$-ATPase & $1-10^{3} ;(-)$ & ND & ND & Brain cortical vesicules/ rat & Phosphate release & [107] \\
\hline NA uptake & $0.005-10.000 ;(-)^{*}$ & ND & ND & $\begin{array}{l}\text { Hippocampus/corpus striatum/ } \\
\text { rat }\end{array}$ & $\begin{array}{l}\text { Method: Coyle and Snyder } \\
(1969) /[3 \mathrm{H}]-\mathrm{NA}\end{array}$ & [108] \\
\hline Thymidine uptake & $10^{-2}-1 ;(-)$ & 0.19 & ND & EOC-20 microglia/ mouse & $\begin{array}{l}\text { Scintillation counting/ } \\
{[3 \mathrm{H}] \text {-thymidine }}\end{array}$ & [106] \\
\hline Choline uptake & $0.24-240.00 ;(-)$ & 15.9 & ND & Hippocampus synaptosome/rat & Method: Whittaker et al. (1964) & [109] \\
\hline
\end{tabular}

$\mathrm{AMT}=$ anandamide membrane transporter; $\mathrm{Mg}^{2+}$-ATPase = magnesium-activated adenosine triphosphatase; $\mathrm{NA}=$ noradrenaline; $\mathrm{ND}=$ not described; $(+)=$ stimulation; $(-)=$ inhibition

*Estimated from plots in cited paper

unlikely to be reached in vivo and so are unlikely to be physiologically meaningful [17].

In addition to reports of TRPV1 receptor agonism, CBD has also been reported to interact with the TRPV2 receptor. In the first study reporting such effects [96], CBD agonized human TRPV2 receptors overexpressed in HEK293 cells when assessed using a fluorescence-based assay, a finding subsequently confirmed using patch clamp electrophysiology and extended to reveal similar effects upon rat TRPV2 overexpressed in the same cell line, although with markedly different potency $\left[\mathrm{EC}_{50}=3.7 \mu \mathrm{M}\right.$ (human) $v s 31.7 \mu \mathrm{M}$ (rat)] (Table 3). CBD effects upon rat TRPV2 receptors were also separately investigated in the same expression system and using patch clamp electrophysiology [98]. Here, similar results were obtained where CBD activated TRPV2 at concentrations $\geq 10 \mu \mathrm{M}$, although a complete concentration-response relationship was not. Subsequently, TRPV2-mediated effects of CBD upon the chemosensitivity of a glioblastoma multiforme cell line to conventional cytotoxic agents were reported [100]. Interestingly, in addition to activating TRPV2, CBD also stimulated TRPV2 expression in this cell line. Finally, such TRPV2-dependent effects of CBD in malignant cell lines were extended by a similar demonstration of CBD-induced increases in chemosensitivity in a multiple myeloma cell line [111]. In both cases, TRPV2-mediated effects of CBD in malignant cells required moderate micromolar concentrations $(\geq 20 \mu \mathrm{M})$ to achieve significant effects.

A single report has also described CBD effects at rat TRPV3 and TRPV4 receptors expressed in HEK293 cells where it acted as a potent agonist in both cases (Table 3), although with variable efficacy when compared with positive controls (TRPV3: 50\%; TRPV4: 16\%) [71].

Several reports have also described CBD interactions with the transient receptor potential ankyrin type 1 (TRPA1) receptor. A first report stated that CBD acts as a potent and efficacious agonist at rat TRPA1 receptors overexpressed in HEK293 cells (Table 3), as assessed using a fluorescencebased assay, but went on to report that high concentrations $(\geq 100 \mu \mathrm{M})$ of CBD failed to elicit $\left[\mathrm{Ca}^{2+}\right]_{\mathrm{i}}$ increases in mustard oil-sensitive dorsal root ganglion neurons [97]. Thereafter, CBD was reported to activate fully rat TRPA1 expressed in HEK293 cells when assessed in a similar fluorescence-based assay, but with much lower potency $\left(\mathrm{EC}_{50}=81.4 \mu \mathrm{M}\right.$; Table 3) [96]. Subsequently, the first report was recapitulated by the same group and reported similar effects of CBD at rat TRPA1 in HEK293 cells but extended the study to show that CBD can also act as a potent desensitizer $\left(\mathrm{IC}_{50}=0.16 \mu \mathrm{M}\right)$ of this receptor [97]. Finally, CBD effects at TRPA1 receptors expressed in HEK293 cells were assessed using patch clamp electrophysiology where $\mathrm{CBD}(\geq 10 \mu \mathrm{M})$ evoked a ruthenium 
red-sensitive bidirectional conductance, although a full concentration-response relationship was not presented. The highest concentration of CBD tested $(30 \mu \mathrm{M})$ was only able to induce a TRPA1-mediated current that was $\sim 20 \%$ of that evoked by the positive control TRPA1 agonist, mustard oil, and was rapidly desensitized by continued exposure to CBD [98].

Finally, $\mathrm{CBD}$ has been reported to act as a potent antagonist (Table 3 ) at the rat TRP subfamily M (TRPM8) receptor expressed in HEK293 cells [71, 97].

\section{VDAC1 (Mitochondrial Porin)}

CBD has also been reported to act upon sheep liver VDAC1. VDAC1 is a promiscuous ion channel, also known as mitochondrial porin, and is most often located on the outer membrane of mitochondria, although has also been reported to be present on cell plasma membranes [112]. VDAC1 plays a complex and important role in a variety of cell functions such as ATP rationing, $\mathrm{Ca}^{2+}$ homeostasis, apoptosis, and protection against oxidative stress. The effect of CBD upon VDAC1 channels reconstituted into an asolectin-based planar lipid bilayer has been examined using patch clamp electrophysiology [84]. Here, CBD $(20 \mu \mathrm{M})$ inhibited VDAC1-mediated currents to varying extents at different voltage steps $(-60 \mathrm{mV}$ to $+60 \mathrm{mV}$ ). This functional finding was further confirmed via a thermophoretic analysis, which demonstrated an interaction between CBD and VDAC1 with a $\mathrm{K}_{\mathrm{d}}$ of $11.2 \mu \mathrm{M}$ (Table 3).

\section{Voltage-gated Calcium Channels (VGCCs)}

CBD has been reported to inhibit human T-type voltage-gated calcium channels (VGCCs) encoded by the $\mathrm{Ca}_{\mathrm{v}} 3$ gene family when expressed in HEK293 cells and assessed using patch clamp electrophysiology [95]. CBD was able to abolish fully conductances via $\mathrm{Ca}_{\mathrm{V}}$ 3.1, 3.2 and 3.3 T-type channels with comparable potency for $\mathrm{Ca}_{\mathrm{V}} 3.1,3.2$ but lower potency for $\mathrm{Ca}_{V} 3.3$ (Table 3). This finding was extended to investigation of CBD effects upon native T-type conductances in mouse trigeminal ganglion neurons where similar inhibitory effects were observed, although a complete concentration response relationship was not described.

\section{Voltage-gated Sodium Channels}

CBD can block voltage-gated sodium channels (VGSCs) in a number of in vitro assays but, interestingly, this VGSC blockade per se does not confer anticonvulsant effects in wholeanimal models of seizure [113]. Here, the effects of CBD $(1-10 \mu \mathrm{M})$ were examined in rat brain slices, cultured mouse cortical neurons, and human SH-SY5Y cells using patch clamp electrophysiology and in Chinese hamster ovary cells expressing human $\mathrm{Na}_{\mathrm{V}} 1.1$ and $\mathrm{Na}_{\mathrm{V}} 1.2 \mathrm{VGSC}$ subtypes using a fluorescence-based assay. In all in vitro tests, CBD inhibited VGSC conductances at micromolar concentrations, although the block was sudden with no apparent conventional concentration-response relationship. This was response is suggestive of a nonspecific effect (e.g., disruption of the lipid membrane in which the channels are located) and was also seen for the structurally similar plant cannabinoid, cannabigerol. When compared in a model of generalized seizure, CBD was strongly anticonvulsant but cannabigerol exerted no effect, suggesting that the apparent in vitro block of VGSC by CBD and cannabigerol are artefactual.

\section{Transporter Targets}

Our review of the current literature revealed 9 investigations of the effect of CBD upon 13 specific transporter targets, which accounts for $20 \%$ of the known molecular targets of CBD (Fig. 1). These are further illustrated in Table 4.

\section{Neurotransmitter Transporters}

The uptake of neurotransmitters is vital to homeostasis in the brain and prevents overstimulation of receptors, which can result in cell death [114]. A major route for neurotransmitter uptake is through transporter proteins, which shuttle specific transmitters. Work in the 1970s utilized rat brain synaptosomes to determine the effect of CBD on the activity of various transporters (Table 4) [115]. Here, CBD $(1-100 \mu \mathrm{M})$ showed a concentration-dependent effect, significant at 50 $\mu \mathrm{M}$, on 5-HT, noradrenaline (NA), and $\gamma$-aminobutyric acid (GABA) uptake, with greater potency for inhibition of 5-HT and NA uptake (50 $\mu \mathrm{M} \mathrm{CBD} ; 78 \%$ and $81 \%$ inhibition, respectively). No significant changes were recorded for $1 \mu \mathrm{M}$ $\mathrm{CBD}$, which draws on concerns regarding the physiological relevance of these data. A more recent study employed rat hippocampal and striatal synaptosomes to investigate the roles of CBD on neurotransmitter uptake [116]. By measuring radiolabelled uptake of NA and dopamine, significant inhibition of NA and dopamine was observed by $1 \mu \mathrm{M}$ CBD in both brain regions investigated.

With regard to dopamine transport, further studies showed a dose-dependent reduction in dopamine uptake following application of CBD $\left(0.5-100.0 \mu \mathrm{M} ; \mathrm{IC}_{50}=16.2 \mu \mathrm{M}\right)$ in rat striatal synaptosomes, consistent with a previous study (Table 4) [105]. Glutamate uptake was again inhibited in a dose-dependent manner following application of CBD (1$100 \mu \mathrm{M})$ to rat striatal synaptosomes. However, unlike CBD's effect on dopamine uptake, half maximal inhibition was achieved at the higher concentration of $43.8 \mu \mathrm{M}$ [105]. These studies indicate that CBD can inhibit uptake of adenosine, dopamine, and glutamate in vitro, but with variable potency. While examining the anticonvulsant properties of CBD some investigation of the cholinergic system was undertaken 
but did not reveal significant changes in choline uptake across several brain regions following $60 \mathrm{mg} / \mathrm{kg}$ intraperitoneally administered CBD [117]. This finding was in contrast to in vitro observations where an $\mathrm{IC}_{50}$ of $15.9 \mu \mathrm{M}$ was reported for CBD upon choline uptake in a rat hippocampal preparation. This study highlights the need for caution in interpreting in vitro assays and extrapolating and/or making assumptions regarding the in vivo effects of CBD.

Microglia act as macrophages of the CNS, and are thought to serve as the first and main form of active immune defense. In previous studies, CBD has been shown to exert anti-inflammatory effects, but a distinct mechanism of action for this effect remains unresolved [106], despite hypotheses that CBD exerts anti-inflammatory effects by facilitating adenosine transmission $[10,106]$. To test this hypothesis, the effect of CBD on the uptake of $\left[{ }^{3} \mathrm{H}\right]$-adenosine was investigated (see Table 4 ). In vitro studies on EOC 20 rat microglia demonstrated that CBD (1-1000 nM) inhibited adenosine uptake in a dosedependent manner. A similar effect was observed in RAW264.7 macrophages where a $K_{i}$ of $225 \mathrm{nM}$ was reported. Further studies, which examined the affinity of CBD for the equilibrative nucleoside transporter 1 (ENT1) showed that CBD displaced radiolabelled 6$S$-[(4-Nitrophenyl)methyl]-6-thioinosine $\left(\left[{ }^{3} \mathrm{H}\right]-\mathrm{NMBPR}\right)$ with a $\mathrm{K}_{\mathrm{i}}$ value of $237 \mathrm{nM}$, consistent with the result obtained from RAW264.7 macrophages. These findings indicate that CBD can inhibit adenosine uptake by binding ENT1 [106]. Thus, while it is clear that CBD can modulate adenosine signaling at both the receptor (see "Receptors") and transporter levels, the contribution of these effects to the in vivo pharmacology of CBD still requires definitive study.

\section{Anandamide Transporters}

CBD has been implicated in modulating the metabolism of the endocannabinoid, arachidonoylethanolamide (AEA; also 'anandamide') in vitro $[118,119]$. Transporter proteins are involved in regulating AEA-mediated cellular signaling and have also been reported to be targets for CBD $[19,71]$.

CBD inhibits the anandamide membrane transporter, which is thought to be responsible for the reuptake of AEA into cells prior to degradation [110]. Scintillation counting of $\left[{ }^{3} \mathrm{H}\right]$-AEA revealed that CBD inhibits AEA uptake in a concentration-dependent manner within a range of 5 to $50 \mu \mathrm{M}\left(\mathrm{IC}_{50}=22 \mu \mathrm{M}\right)$ in rat basophilic leukemia cells (RBL-2H3) [19]. Using the same technique and cell line, these findings were replicated by De Petrocellis et al. [71], where the $\mathrm{IC}_{50}$ obtained was $25.3 \mu \mathrm{M}$, although the CBD concentration range tested was 1-25 $\mu \mathrm{M}$ [71]. Previous studies undertaken by Di Marzo et al. [120] have shown that AEA exerts anti-inflammatory effects. Therefore, the anti-inflammatory effects also exerted by CBD may arise from facilitation of AEA transmission [19].

Overall, while the concentrations at which effects on AEA transporters have been reported are relatively high, it remains possible that incomplete inhibition by CBD could underlie some effects in vivo.

\section{Multidrug Resistance Transporters}

$\mathrm{ABCC} 1$ or multidrug resistance-associated protein 1 , is a transporter expressed in various tissues and displays a wide substrate specificity, including important therapeutics. Investigating intracellular substrate retention, using Fluo3 and vincristine, $\mathrm{CBD}\left(\mathrm{IC}_{50}=128.3 \mu \mathrm{M}\right.$ and 30.9 $\mu \mathrm{M}$, respectively) was reported to be a "potent" inhibitor of ABCC1-meditated transport in vitro [103]. The use of the word potent in this regard is questionable given the reported $\mathrm{IC}_{50}$. Previous work by this group [104] using flow cytometric analysis of substrate accumulation and ATPase activity assays also highlighted the ABCG2 transporter as a molecular target for CBD. Again, inhibition was demonstrated in the presence of 10 and $50 \mu \mathrm{M}$ CBD (Table 4). The ATP-dependent transporter Pglycoprotein has also been implicated in CBD effects [121]. ATPase assays revealed a CBD concentrationdependent inhibition of transport activity mediated by Pglycoprotein $\left(\mathrm{IC}_{50}=39.6 \mu \mathrm{M}\right)$. All these studies highlight in vitro evidence that adds these substrate transporters to the list of molecular targets; however, in vivo evidence is still lacking.

\section{Mg-ATPase Transporter}

Magnesium-activated ATP $\left(\mathrm{Mg}^{2+}\right.$-ATPase $)$ is a transporter that is expressed in erythrocytes, where $\mathrm{Mg}^{2+}$ flows through the plasma membrane to drive ATP hydrolysis [122]. In vesicles obtained from the rat cortex, CBD was reported to be a potent inhibitor of $\mathrm{Mg}^{2+}$-ATPase within a range of 1 $1000 \mu \mathrm{M}$ [107].

\section{Part 2: The Relevance of CBD Molecular Targets in Neurological Disorders}

Part 1 considered the available pharmacological evidence describing CBD's effects at specific molecular targets, regardless of any a priori evidence of their involvement in a given disease or disorder. Here, in part 2, we consider whether: 1) there is a role for each of CBD's plausible pharmacological targets in neurological disease; and whether 2) CBD's modulation of a given target would be beneficial or detrimental. 


\section{Epilepsy}

Epilepsy is a highly heterogenous neurological disease characterized by the manifestation of spontaneous recurrent seizures and has a significant unmet clinical need whereby $>$ $30 \%$ of people with epilepsy do not gain full control of their seizures from currently available treatments [123]. Cannabis has a long anecdotal history of use for the treatment of epilepsy, although, confusingly, significant reports of proconvulsant effects are also present in the literature (for a detailed review see [124]). CBD has a more consistent record and has been repeatedly shown to exert anticonvulsant effects in a variety of preclinical models and small, but flawed, clinical trials but the mechanism through which these effects are exerted remains to be determined [124]. Here, we consider the potential role that the pharmacological targets identified in part 1 can play in epilepsy and its symptoms.

\section{CBD Ion Channel Targets in Epilepsy}

While CBD's effects at TRPV channel subtypes have been investigated with some rigor, the involvement of this subtype of TRP channel in epilepsy remains unclear. In humans, 2 reports describe increases in TRPV1 mRNA and protein expression in small numbers of patients with mesial temporal lobe epilepsy, tuberous sclerosis, and focal cortical dysplasia type IIb, suggesting that TRPV1 may be involved in epilepsy [125]. However, it remains unclear whether the increased TRPV1 expression described reflects an uninvolved and downstream consequence of disease or an integral part of the process. The preclinical literature describing TRPV1 involvement in epilepsy is conflicted where studies suggest no involvement [126, 127], a proconvulsant effect, or an anticonvulsant effect of TRPV1 activation [128-134]. Overall, a larger number of studies suggest that the consequences of TRPV1 activation in epilepsy are detrimental which, given the large number of validated studies asserting overwhelmingly anticonvulsant effects of CBD in these animal models, suggests that TRPV1 activation by CBD is not part of its antiepileptic mechanism of action. To our knowledge, neither TRPV2 nor TRPV3 have been reported to have any involvement in epilepsy, while only a single study to date has suggested the involvement of TRPV4 in epilepsy [135]. Here, TRPV4 blockade was proposed to reduce febrile seizures in larval zebrafish [136], and so, again, the ability of CBD to activate TRPV4 would be in direct contrast to its clear anticonvulsant effects.

With regard to other TRP family members, only a single preclinical report associates TRPA1 expression changes with epilepsy without insight into any causal relationship, and no reports linking TRPM8 and epilepsy have been made [137].

Finally, the potential conflict between TRP agonistmediated increases in $\left[\mathrm{Ca}^{2+}\right]_{\mathrm{i}}$ and anticonvulsant effects of CBD should be considered alongside the propensity for many
TRP agonists to elicit $\mathrm{Ca}^{2+}$-dependent desensitization, including CBD in some cases [98, 137]. However, it remains to be seen whether a hypothetical CBD-induced TRP channel desensitization achieved from steady-state CBD dosing could contribute to the antiepileptic effects reported. In conclusion, based on the existing evidence, the TRP channels affected by CBD are unlikely to account for the antiepileptic effect seen.

Although the literature makes few direct links between VDAC1 and epilepsy, and such that exist remain limited to the hypothetical, mitochondrial dysfunction that plays a significant role in some epilepsies [138, 139]. Therefore, while VDAC1 remains a plausible molecular target for CBD, it is too early to assert confidently any involvement of VDAC1 in the mechanism of action underlying CBD's antiepileptic mechanism but should be investigated further. Related to VDAC1 as a mitochondrial target is the effect of CBD via $\operatorname{PPAR} \gamma$, a nuclear receptor type expressed in brain with a significant role in regulating metabolism, immune response, and development. However, while such a physiological role could have profound implications for epilepsy, no specific link between PPAR $\gamma$ and epilepsy has yet been made, and direct effects of CBD at (c.f., via) this target have yet to be demonstrated [140].

While VGCCs are long-established molecular targets for antiepileptic drugs (AEDs) such as lamotrigine, eslicarbazepine, felbamate, levetiracetam, gabapentin, and pregabalin, most target N-, P/Q-, and L-type VGCCs and not the low voltage-activated T-type VGCCs which CBD can block [141]. T-type channels are, however, blocked by a smaller number of existing AEDs such as ethosuximide, zonisamide, and possibly valproate, where this action is thought to inhibit synchronized depolarization of neuronal populations which can lead to generalized seizures [141]. Such drugs have found particular utility in the treatment of absence seizures, while T-type VGCC mutations have been associated with the pathogenesis of some absence epilepsies [142]. Thus, while a definitive role for blockade of T-type $\mathrm{Ca}^{2+}$ channels in the antiepileptic mechanism of CBD has not been established, both CBD's potency at this target and the target's validity in this disease make it a plausible target for further investigation. It is also notable that CBD's effects at Ttype channels produces a hyperpolarizing shift of the activation potential, while changes in steady-state activation and activity, even at strongly hyperpolarizing potentials, suggest the ability to induce a block when the channel is in either the open or closed state. Interestingly, while ethosuximide induces a similar hyperpolarizing shift, it is only able to block channels when in the open state [143].

\section{CBD Receptor Targets in Epilepsy}

CBD exhibits reasonable affinity at plausible concentration for $5-\mathrm{HT}_{1 \mathrm{~A}}$ and $5-\mathrm{HT}_{2 \mathrm{~A}}$ receptors, and $5-\mathrm{HT}_{2 \mathrm{~A}}$ receptors act 
as a target for fenfluramine, a drug for which some evidence exists supporting efficacy in drug-resistant epilepsies such as Dravet syndrome [144]. A very limited number of studies have reported changes in 5-HT receptor expression and function in people with epilepsy, although it remains unclear whether this is a consequence of the disease or a component of pathogenesis. Thus, while 5-HT involvement in pathogenesis remains uncertain, some 5-HT receptor subtypes may represent a valid therapeutic target in epilepsy through which CBD could be acting $[145,146]$.

GlyR are predominantly expressed in the CNS in neuronal cells in the brainstem and spinal cord and, as such, there is much less evidence of their role in disorders of the cerebrum, such as epilepsy. However, recent research in rodent species has shown significant, functional GlyR expression in cortex and hippocampus at least up to postnatal day 14 where they serve to modulate neuronal network function [147], and emerging evidence suggests a role in hyperexcitability disorders [148]. These findings suggests that investigation of GlyR function in healthy and epileptic, mature human cortex is warranted in order to lend further credence to GlyR-mediated antiepileptic effects of CBD.

Links between $\mu$ and $\delta$ OR function and a variety of brain disorders, including epilepsy, have been extensively investigated $[149,150]$. However, OR agonism and antagonism have each been confusingly associated with both pro- and anticonvulsant effects, and so make any antiepileptic therapeutic strategy involving OR targets uncertain. Moreover, the relatively high micromolar concentrations at which CBD exerts a block of $\mu$ and $\delta$ OR in highly refined and optimized systems (see Part 1) further argues against this mechanism underlying the drug's well established antiepileptic effects [151].

GPR55 is an orphan receptor for which the endogenous ligand lysophosphatidylinositol has been proposed where GPR55 activation triggers release of $\mathrm{Ca}^{2+}$ from intracellular stores to facilitate neurotransmission in hippocampus [51]. However, while this functional role for GPR55 in modulating synaptic transmission has been demonstrated, its validity as a target for modulation of hyperexcitability disorders such as epilepsy remains unknown. CBD shows good affinity for GPR55 and the antagonistic effects reported would be consistent with an attenuation of synaptic transmission which could be antiepileptic. However, definitive evidence to support this antiepileptic mechanism of action is required.

nAChRs have been directly implicated in a rare, familial form of epilepsy, autosomal dominant nocturnal frontal lobe epilepsy where mutant forms of the $\alpha 4 \beta 2 *$ subtype are widely expressed in cortex and, more generally, $\alpha 4$ subunit mutations are associated with febrile seizures [152]. However, the role of these mutant $\mathrm{nAChRs}$ during brain development to produce this epilepsy or influence febrile seizure susceptibility remains unclear [153].Thus, while nAChRs are a plausible target for
$\mathrm{CBD}$, their relevance in ictogenesis and hence the therapeutic effect of the drug remains unknown.

CBD has also been shown to mediate effects via both $\mathrm{A}_{1}$ and $\mathrm{A}_{2}$ adenosine receptors in studies of peripheral tissues. However, both receptor subtypes are present in brain, and adenosinergic modulation of neuronal activity serves to protect against cellular damage resulting from excessive metabolic demand (e.g., during seizures) in addition to many agonists at these receptors exerting significant anticonvulsant effects in a wide range of animal models [154]. However, exploitation of adenosine agonists as epilepsy treatments has been unsuccessful owing to the very narrow therapeutic window that can result in significant adverse events. In particular, those affecting the cardiovascular system in humans and in animal models, which suggests that direct agonism of $A_{1} / A_{2}$ receptors by CBD is unlikely and, as such, indirect elevation of local adenosine levels is not only more plausible but could represent a viable mechanism underlying CBD's anticonvulsant effects $[124,155]$.

\section{CBD Enzyme Targets in Epilepsy}

While CYP enzymes are present in the endoplasmic reticulum of CNS cells, their expression is typically only $0.5 \%$ that seen in hepatic tissues [156]. Moreover, while CNS CYP450 have been shown to modulate GABA and cholesterol levels, it is unclear whether a drug effect on CNS CYP450 would confer a functional change in CNS function through such pathways [156].

AANAT has not been implicated in epilepsy and so the pertinence of this target is unknown. Moreover, while neuroinflammation has long been established as a hallmark consequence of epilepsy and PLA2 levels are reportedly increased in some animal models and human studies of epilepsy, the relevance of this enzyme as a therapeutic drug target remains uncertain [157]. Similarly, reported effects upon COX and IDO enzymes could also be argued to exert effects upon epilepsy via involvement in inflammatory processes. However, conflicting results and the very high CBD concentrations required for such effects casts doubt over the relevance of these targets for CBD's effects in epilepsy.

Conversely, FAAH inhibition has been shown to affect seizure states in animal models and so represents a putative antiepileptic target $[158,159]$. However, as CBD has been claimed to inhibit and activate FAAH, conclusive elucidation of CBD's effects at this target are required. Furthermore, as antiepileptic effects of FAAH result in $\mathrm{CB}_{1} \mathrm{R}$-mediated anticonvulsant effects and such effects are prone to tolerance, investigation of the persistence of FAAH-mediated interventions in epilepsy is also required.

Finally, while not exerting a direct therapeutic effect, it should be noted that CBD-induced inhibition of enzymes such as CYP3A4, which is responsible for the hepatic metabolism 
of a variety of AEDs and can be induced by others [160], could exert an indirect effect by altering circulating levels of concurrent medications. The clinical relevance for such indirect effects of CBD on circulating AED levels has recently been highlighted in the case of clobazam co-administration [161].

\section{CBD Transporter Targets in Epilepsy}

While CBD's reported inhibition of glutamate reuptake is entirely inconsistent with is well established antiepileptic effects, the inhibition of dopamine and adenosine reuptake could play a role as increased levels of both transmitters have been associated with anticonvulsant effects $[6,162]$. Nevertheless, the high micromolar concentrations of CBD required to elicit these effects for some targets suggests that further investigation of physiologically pertinent concentrations at defined molecular targets is required to clarify their involvement, if any.

CBD reportedly inhibits AEA uptake, although the specific molecular transporter responsible for this role remains to be identified. Moreover, in the CNS, AEA is less abundant than the other major endocannabinoid, 2-arachidonoyl glycerol, which renders a functional role for AEA uptake inhibition in the antiepileptic effects of CBD uncertain [163]. Furthermore, AEA uptake inhibition would lead to increased $\mathrm{CB}_{1} \mathrm{R}$ activation that could conceivably produce psychoactive effects that have never been reported for CBD. Moreover, as describe above ("CBD Enzyme Targets in Epilepsy"), $\mathrm{CB}_{1} \mathrm{R}$-mediated modulation of seizure states is prone to treatment tolerance, which does not appear to occur with prolonged CBD treatment in animal models.

\section{Movement Disorders}

Movement disorders cover a wide range of diseases that hinder the ability to initiate and control movement. CBD has been shown to alleviate the symptoms of dystonia, dyskinesia, and catalepsy resulting from antipsychotic treatment or neurodegenerative diseases [164, 165].

\section{CBD Ion Channel Targets in Movement Disorders}

It is known that CBD acts on multiple subtypes of TRPV channels, and TRPV1 agonists, such as capsaicin, have been shown alleviate hyperkinesia in rodent models of Huntingdon's disease (HD) by restoring the neurochemical deficits $[164,165]$. CBD also desensitizes the TRPV1 receptor, so it is not certain if TRPV1 serves as a plausible target. At present, neither TRPV2 nor TRPV3 receptors have been reported to play a role in movement disorders. One study has shown that TRPV4 R269H mutations are responsible for essential tremors in Charcot-Marie-Tooth disease. However, TRPV4 does not serve as a suitable target for CBD, as high micromolar concentrations $(100 \mu \mathrm{M})$ are required for channel blockade [71]. Regarding other TRP subtypes, no studies linking TRPA1 or TRPM8 to movement disorders have been made. Based on the data so far, it is unlikely that interactions between CBD and TRP channels account for its antihyperkinetic effects.

Current evidence proves that CBD changes the conductance of VDAC1 [84]. VDAC1 plays a significant role in Parkinson's disease (PD), where it is required for the degradation of mitochondria. This causes the loss of dopaminergic neurons, leading to the movement disorders seen in PD [166]. Thus, VDAC1 may be involved in the effect of CBD in movement disorders.

Activation of PPAR $\gamma$ by pioglitazone has been reported to reverse oral dyskinesia in rodent models of schizophrenia, but adverse effects on memory retention have been observed [167]. CBD has been shown to upregulate and activate $\operatorname{PPAR} \gamma[18,54]$, and therefore it may be able to replicate the effects of pioglitazone.

CBD acts as a potent inhibitor of T-type VGCCS [95]. Ttype VGCC $\alpha 1 G$ (CACNA1G) subunit expression is significantly increased in Purkinje cells in rodent models of ataxia, which results in the abnormal regulation of motor function [168]. Numerous studies on rodent models have also shown that palatal, Parkinsonian, and essential tremors are all dependent on T-type VGCC conductance [169, 170]. Tremors were abolished upon channel blockade by zonisamide, a selective T-type VGCC antagonist [171]. T-type VGCCs are blocked by CBD at low doses, and therefore CBD may be effective in treating the diseases mentioned.

\section{CBD Receptor Targets in Movement Disorders}

CBD activates $5-\mathrm{HT}_{1 \mathrm{~A}}$ and $5-\mathrm{HT}_{2 \mathrm{~A}}$ receptor isoforms with reasonable potency [26]. Activation of the $5-\mathrm{HT}_{1 \mathrm{~A}}$ subtype by buspirone has been shown to alleviate catalepsy in rodent models of PD [172]. Similar results were observed following CBD treatment, where the effect of CBD was abolished by 5$\mathrm{HT}_{1 \mathrm{~A}}$ receptor blockade, but it is not clear if CBD directly interacted with $5-\mathrm{HT}_{1 \mathrm{~A}}$ to exert its anticataleptic effect [50]. Despite this, the $5-\mathrm{HT}_{1 \mathrm{~A}}$ subtype seems to be a suitable therapeutic target for the anticataleptic action of CBD.

GlyRs are expressed in the CNS, where they mediate inhibitory neurotransmission. Disorders in glycine transmission have been implicated in spastic disorders, for example research in the 1980s showed a loss of glycine synthesis in the spinal cord of spastic animals [173]. High micromolar concentrations of $\mathrm{CBD}$ are required to activate GlyRs; therefore, GlyRs are not appropriate targets for CBD.

Present research shows that blockade of $\delta$ ORs and $\mu$ ORs abolishes the extrapyramidal effects of levodopa treatments in humans [174]. However, high micromolar concentrations of $\mathrm{CBD}$ are required to antagonize either receptor subtype, so 
$\mu \mathrm{ORs}$ and $\delta \mathrm{ORs}$ are not plausible targets for CBD [28]. There is no evidence linking the GPR55 receptor with movement disorders.

$\mathrm{A} 4 \beta 2$ and $\alpha 7 \mathrm{nAchRs}$ are potently inhibited by CBD [27]. As rapid desensitization of either subtype reduces dyskinesia [174], it is possible that the blockade of these receptors by CBD is responsible for its antidyskinetic effect.

$\mathrm{CBD}$ has been reported to modulate adenosinergic activity in vitro. However, no current studies that link the $\mathrm{A}_{1}$ receptor with movement disorders have been undertaken. Adenosine $\mathrm{A}_{2 \mathrm{~A}}$ receptors are highly expressed in GABAergic neurons within the indirect pathway of the basal ganglia, where their activation exerts an inhibitory effect on movement. Blockade of the $\mathrm{A}_{2 \mathrm{~A}}$ receptor in Parkinsonian rats abolished the motor deficits. The side effect profile was favorable owing to low $\mathrm{A}_{2 \mathrm{~A}}$ receptor expression in other regions of the brain [111]. As CBD activates $A_{2 A}$ receptors, this interaction is unlikely to have any beneficial effect in PD.

\section{CBD Enzyme Targets in Movement Disorders}

CBD is a potent inhibitor of CYP2D6 [60]. Following treatment with various antipsychotic agents, tardive dyskinesia appeared to be greater in patients with the poor metabolizer phenotype of CYP2D6, but the difference was not statistically significant [175]. It is not clear if the inhibition of CYP2D6 by CBD will be beneficial in preventing antipsychotic-induced tardive dyskinesia. No other CYP450 subtypes have been investigated in movement disorders. AANAT and COX2 have not been implicated in movement disorders; high CBD concentrations are required to an interaction with either enzyme, thus they are not suitable targets. Studies investigating the use of FAAH inhibitors to treat restless leg syndrome and periodic limb movement disorder are ongoing, but no publications have been released so far.

\section{CBD Transporter Targets in Movement Disorders}

CBD inhibits the uptake of glutamate, dopamine, and adenosine, but only at high micromolar concentrations [105]. Impaired glutamate uptake has been reported in transgenic rodent models of $\mathrm{HD}$, but the effect of this on motor function has not been determined [176]. Dopamine transporter availability is significantly lower in patients exhibiting symptoms of PD [177]. Adenosine uptake has not been implicated in this disease. Based on the data so far, inhibition of glutamate or dopamine uptake will not be beneficial in the treatment of movement disorder.

CBD binds an unknown AEA transporter to inhibit AEA uptake $[19,71]$. Blockade of AEA uptake by UCM707 abolished hyperkinesia in rodent models of HD and reduced spasticity in MS rats [178]. However, the elevation in AEA could produce psychotropic effects and tolerance upon $\mathrm{CB}_{1} \mathrm{R}$ activation [179], which has not been seen as a side effect of CBD [180]. Therefore, the binding of CBD to the AEA transporter will not provide a therapeutic effect in movement disorders.

\section{Neurodegenerative Diseases}

Several preclinical studies have shown that CBD can exert benefit in mouse models of neurodegenerative disease [181, 182]. A common finding among neurodegenerative diseases is chronic neuroinflammation and initiation of positive feedback between failure of calcium homeostasis, mitochondrial dysfunction, and excessive cell death, where age and oxidative stress are strong correlates [183-185]. Dementia is caused by many different disorders, resulting in deterioration of memory, mental functions, and behavior. It was estimated that, globally, in 2010, 35.6 million people were living with it - and it was predicted that this number would double every year: Alzheimer's disease (AD) is generally considered to be the most common subtype, resulting in $60-80 \%$ of cases [186]. As it is associated with the excessive build-up of $\beta$-amyloid $(A \beta)$ and hyperphosphorylated forms of the microtubuleassociated protein, tau, this led to the proposal of the "amyloid cascade hypothesis" as the underlying pathogenic basis for this disease [187]. However, manifestation of $\mathrm{AD}$ can be highly heterogeneous with clear gene-environment interactions [188], and precipitating are factors highly variable, that is, any insult leading to an excessive and chronic neuroinflammatory response (e.g., traumatic brain injury) or energy failure [189], which is often seen in early-onset neurodegenerative diseases, such as Leigh syndrome [190]. Genome-wide analysis has highlighted several risk genes, many of which alter clearance of misfolded proteins and modulate inflammation, while environment also influences expression via systemic inflammation (e.g., obesity), which may make targeting risk factors and the immune system important treatment strategies [191].

\section{CBD Receptor Targets in Neurodegeneration}

It has been suggested that the ECS may be hypofunctional, and/or dysfunctional in neurodegenerative diseases, suggesting circumstance-dependent protective or potentially damaging effects (reviewed in [192, 193]) and consistent with its largely adaptive role in mammalian physiology.

In relation to CBD, McPartland et al. [16] conclude that CBD does not act directly at $\mathrm{CB}_{1} \mathrm{R}$ but may act indirectly at potentially supraphysiological concentrations by enhancing ECS tone. However, as discussed in the transporter section (see below), CBD may also bind to fatty acid binding proteins 
(FABPs), which could partly explain its apparent indirect effects on the ECS among others [194].

As indicated in Table 1, CBD exerts effects via 5-HT receptors and the serotonergic system, including the $5-\mathrm{HT}_{1 \mathrm{~A}}$ receptor. While implicated in neurodegeneration, serotonergic involvement is complex as both increases and decreases in receptor density across various regions of the brain have been associated with cognitive decline [195]. Although not strictly a neurodegenerative disorder, CBD has been shown to be effective in a mouse model of hepatic encephalopathy induced by bile duct ligation - a condition that has a large element of neuroinflammation. In this study, mice received 5 $\mathrm{mg} / \mathrm{kg}$ of CBD or vehicle for 5 weeks after ligation. Treated mice were significantly protected, but the effect was largely negated by co-administration of a $5-\mathrm{HT}_{1 \mathrm{~A}}$ receptor antagonist [196]. However, as there was no bile duct ligation control group treated with the antagonist only, it is not possible to determine if the antagonist was blocking CBD's effects directly, as it could simply be a behavioral effect. Similarly, Pazos et al. [197] showed that in a pig model of hypoxic ischemic brain injury, $\mathrm{CBD}$, at a final concentration in brain tissue of $\sim 0.2 \mu \mathrm{M}$, could be protective when given after the insult. Critically, the protective effects were blocked when a 5- $\mathrm{HT}_{1 \mathrm{~A}}$ antagonist was co-administered with the CBD [197]. However, since no antagonist-only group was included in the study, a clear demonstration of CBD effects via 5HT1A receptors was achieved. There is thus some evidence in vivo that 5-HT may play in a role in CBD's actions, but it is not possible to determine if this effect is directly mediated via this receptor.

$\mathrm{CBD}$ can bind to PPAR $\gamma$, and PPAR $\gamma$ activation is becoming an important target in neurodegeneration, as it is antiinflammatory and its activation improves mitochondrial function and resistance to oxidative stress [54, 140]. Here, the protective effects of $\mathrm{CBD}$ in an $\mathrm{A} \beta$-induced neuroinflammatory mouse model were abolished by a PPAR $\gamma$ antagonist, but no evidence was given as to whether this was a direct or indirect effect [198]. CBD can also positively modulate COX via increased mRNA and protein expression of PPAR $\gamma$ and COX2, which also suggests that a COX2-generated increase in $\mathrm{PGD}_{2}$ and $15 \mathrm{~d}-\mathrm{PGJ}_{2}$ could underlie PPAR $\gamma$ activation in addition to any direct activation of PPAR $\gamma$ by CBD $[18,54,93]$. A possible mechanism for this is suggested by the observation that NRF2 can increase PPAR $\gamma$ expression as CBD can activate NRF2 [79, 199, 200].

CBD can antagonize the GPR55 receptor [20, 51]. This receptor, when activated by its proposed endogenous ligand, lysophosphatidylinositol, appears to be neuroprotective. Activation of GPR55 by a variety of ligands, including lysophosphatidylinositol, can release calcium from intracellular stores [201], and can boost the release of neurotransmitters, such as glutamate at synapses [51]. Critically, activation of GPR55 can stimulate the calcineurin-nuclear factor of activated T cells (NFAT) pathway-a well-known target of calcium signaling [202]. The NFAT pathway is a master regulator of the immune response and is inhibited by ciclosporin, but can also display antiapoptotic actions in neurons [203, 204]. However, $A \beta$-induced neuritic damage, in an in vitro model, mimics the increased intracellular calcium often seen in neurodegenerative disorders and is associated with upregulation of the calcineurin-NFAT pathway, inhibition of this pathway, both in vivo and in vitro, can reverse markers of neurodegeneration [205]. Indeed, in the brains of patients with $\mathrm{AD}$, increased nuclear NFAT is a common finding - and cognitive decline in this disease is associated with selective changes calcineurin/NFAT signaling. This suggests that although GPR55 activation of NFAT can be antiapoptotic in some circumstances, blocking GPR55 with CBD could be beneficial in neuroinflammation, as it might suppresses the calcineurin-NFAT pathway [206].

CBD antagonizes nAChRs and although $\alpha 7$-nAChR agonists have limited use in $\mathrm{AD}$ to improve cognition, in Down's syndrome increased $A \beta_{1-42}$ binding to $\mathrm{nAChRs}$ accelerates $A \beta_{1-42}$ internalization that could worsen neuroinflammation [207]. Thus, there are putative benefits and disadvantages to agonism and antagonism of this receptor that are dependent on the prevailing physiological conditions; both antagonists and agonists can have benefit but also exhibit biphasic effects [207, 208]. At this juncture, it is therefore unclear whether or not this is an important target for CBD.

CBD can act as a positive allosteric modulator of ORs [28, 209]. The opioid system has many functions that could be important in neuroprotection, ranging from control of cellular proliferation to immunomodulation. Although opposing effects can be seen in some circumstances, activation of ORs, in particular, the $\delta \mathrm{OR}$, is considered neuroprotective, especially in hypoxic/ischemic injury, and tends to be immunosuppressive. Certainly, in some animal models of MS and PD, opioid agonists may be effective. However, there are cases of movement disorders occurring in patients after anesthesia and use of opioid drugs, which can be reversed by the opioid antagonist naloxone and so suggests that the role of the opioid system in neuroprotection might be more complex [210]. Thus, the potential role of CBD in modulating neuroprotection via the opioid system remains unclear.

\section{CBD Enzyme Targets in Neurodegeneration}

CBD can directly inhibit enzymes in the ETC in isolated mitochondria [66]. However, brain extracts obtained from rats acutely and repeatedly treated with CBD revealed significantly increased ETC activity [67]. In neurodegenerative disease, the ETC is often impaired [211]. This might therefore suggest that $\mathrm{CBD}$, like many other compounds that can inhibit mitochondrial function, can induce an adaptive upregulation of mitochondrial function and resistance to oxidative stress, a 
well-described process involving reactive oxygen species [212, 213].

CBD can exert biphasic effects on the kynurenine/ tryptophan pathways, causing activation at $<1 \mu \mathrm{M}$ but inhibition at higher concentrations [72]. A key enzyme in this pathway is IDO, which, when activated by inflammatory mediators, might not only increase tryptophan degradation, and thus 5-HT depletion, but also the production of metabolites that could induce oxidative stress [94, 214]. Thus, although there is no direct evidence for inhibition of IDO by CBD, suppression of this pathway could be an attractive approach to reduce neuroinflammation.

As previously mentioned, $\mathrm{CBD}$ can positively allosterically modulate COX, and increased COX1 and COX2 activities are thought to play an important role in the development of neuroinflammation in several neurodegenerative disorders $[93,215]$. However, interpretation is complicated because COX enzymes can also metabolize docosahexaenoic acid/ eicosapentaenoic acid to the anti-inflammatory resolvins [216]. In this regard, it has been suggested that low-dose aspirin, in combination with fish oil, is strongly antiinflammatory because it can allosterically activate COX2, and in the presence of docosahexaenoic acid be protective in $\mathrm{AD}$ [217]. As CBD can upregulate PPAR $\gamma$ and $\mathrm{COX} 2$ at low micromolar doses, it is possible that CBD could have antiinflammatory affects both via PPAR $\gamma$ and resolvins [18].

Finally, one property of CBD that has long thought to be important in its mode of action is its ability to act as an antioxidant and was originally considered to arise from its ability to directly scavenge ROS $[218,219]$. However, the protective effect of CBD has also been associated with an upregulation of $\mathrm{Cu}, \mathrm{Zn}$ superoxide dismutase mRNA, an antioxidant enzyme [220]. Indeed, CBD can activate the redox-sensing factor NRF2, which is key in detecting electrophilic xenobiotics [79, 200, 221]. Mazur et al. [222] have suggested CBD is a good candidate for phase 1 metabolism, as it is very lipophilic, so would be oxidized and thus result in activation of phase II metabolism. It therefore appears that CBD may be both a direct and indirect antioxidant, with the latter effect arising from activation of the xenobiotic system. Because of its antioxidant properties, and its well-described anti-inflammatory effects, it is under investigation for its potential use against neurodegeneration [223].

\section{CBD Ion Channels Targets in Neurodegeneration}

CBD binds to and modulates mitochondrial VDAC1 [84]. VDAC1 levels are elevated in the brains of patients with AD and the protein may interact with $\mathrm{A} \beta$ and phosphorylated tau which supports the idea that both affect mitochondrial function [224]. In contrast, reduced VDAC1 expression appears to protect against $\mathrm{AD}$ [225]. VDAC1 plays a key role in controlling calcium flux into mitochondria, and intracellular calcium can increase VDAC1 expression and oligomerization, which is associated with increased apoptosis; in particular, it is thought that VDAC1 selectively transfers apoptotic calcium signals to the mitochondrion [226, 227]. Two other groups have also shown that CBD could apparently control intracellular calcium flux in a mitochondrially dependent way, which, overall, suggests that $\mathrm{CBD}$, via a VDAC1-related mechanism, could play an important role in controlling calcium flux in neurodegeneration $[228,229]$.

TRP channels have also been extensively investigated as CBD targets where it acts largely as an agonist. Overactivation of TRPV1 has been implicated in neurodegeneration via calcium overload of mitochondria, although the rapid desensitization of TRPV1 following agonist stimulation suggests a plausible longer-term mechanism by which agonists could be neuroprotective [230]. In fact, TRPV1-mediated modulation of presynaptic neurotransmitter release is partly dependent on mitochondrial calcium signaling, and TRPV1 activation can enhance mitochondrial function [231, 232]. That TRPV1 can both enhance and inhibit mitochondrial function can be reconciled by the fact that calcium tightly controls mitochondrial function and biogenesis such that a small amount can stimulate function but too much can induce apoptosis [212, 233]. Finally, vanillin-induced TRPV1 activation reduced markers of oxidative stress in model of HD and improved motor function, suggesting further validity for this target in relation to CBD [234].

\section{CBD Transporter Targets in Neurodegeneration}

CBD can inhibit cellular uptake of adenosine via inhibition of the ENT1 carrier at nanomolar concentrations, and it is now thought that adenosinergic signaling could play a role in neuroprotection [10, 106, 228, 235]. Although possible evidence that CBD might act, in part, via this system was suggested by the observation that in brain slices taken from a newborn mouse hypoxia model that $\mathrm{A}_{2 \mathrm{~A}}$ and $\mathrm{A}_{1 \mathrm{~A}}$ receptor antagonists inhibited a protective $\mathrm{CBD}$ effect, the most significant effect was only observed at $100 \mu \mathrm{M}$ - a physiologically implausible concentration [31]. In contrast, Mecha et al. [10], using a virally induced mouse inflammatory model of MS, demonstrated that an antagonist of the $\mathrm{A}_{2 \mathrm{~A}}$ receptor partially blocked the in vivo ability of CBD to suppress inflammation and immune cell infiltration in the brains of infected mice; the administration of the antagonist on its own had no effect. In cell lines, the antagonist could also block the anti-inflammatory effects of $1 \mu \mathrm{M} \mathrm{CBD}$ in a dose-responsive manner [10]. Thus, there is some evidence that CBD might partially work through increasing adenosine levels, but it does require further research.

Computational analysis and ligand displacement assays suggest that CBD is transported by FABPs, which also transport AEA and so could explain the ability of CBD to increase 
AEA levels; the $\mathrm{K}_{\mathrm{i}}$ of CBD determined by displacement assays was in the region of $1.5-1.9 \mu \mathrm{M}$ for 3 FABPs - which is comparable to AEA in the same assay $(0.8-3.1 \mu \mathrm{M})$ [194]. FABPs are involved in intracellular trafficking of hydrophobic ligands within cells and are thus important in the transport of endogenous lipid and xenobiotics [236]. Although evidence is limited, FABP levels appear to be increased in neurodegenerative states and may be a potential biomarker [237]. Moreover, increased FABP3 expression accentuates arachidonic acid-induced $\alpha$-synuclein oligomerization and cell death [238]. As already discussed, the ECS is thought to be important in neurodegeneration, so the ability of CBD to bind competitively to FABP could indicate that it is an important target.

CBD inhibits $\mathrm{ABCG} 2\left(\mathrm{IC}_{50}=21-30 \mu \mathrm{M}\right)$ and $\mathrm{ABCC} 1$ $\left(\mathrm{IC}_{50}=31-128 \mu \mathrm{M}\right)[103,104]$. ATP-binding cassette transporters, as well as being involved in lipid metabolism, cholesterol efflux, and drug transport, are important in removing intracellular $\mathrm{A} \beta$ and are dysfunctional in $\mathrm{AD}$; as they are ATP dependent, it has been suggested that reduced energy production could lead to a build-up of $A \beta$ [239]. Specifically, both ABCG2 and ABCC1 have been found to be involved in $A \beta$ transport $[240,241]$. Whether or not CBD may beneficially act through these transporters is difficult to gauge, as not only might they inhibit $\mathrm{ABC}$-mediated transport of $\mathrm{A} \beta$, but the reported $\mathrm{IC}_{50}$ may also be too high to be relevant physiologically.

CBD can inhibit both dopamine and glutamate uptake [105]. The dopaminergic system is involved in some stages of $\mathrm{AD}$, for instance its degeneration can result in apathy and although its precise role is still debated, agonists can be of some benefit [242]. Glutamate, as the major excitatory neurotransmitter, has long been associated with neurodegeneration but its ultimate effect is very much dependent upon the glutamate receptor subtype mediating its effects; some can be protective while others exacerbate damage [243]. Thus, CBD might have some beneficial effect on dopamine levels, but the higher concentrations required for effects on glutamate suggest that this is less likely to be an important mechanism.

Finally, CBD inhibits low-density lipoprotein-induced cholesteryl ester formation in cultured human fibroblasts, not via direct inhibition of ACAT but possibly via increased cholesterol transport out of the cell-an effect that was apparent from 10 to $30 \mu \mathrm{M}$ in cell culture [64]. This suggests that it might modulate cholesterol metabolism - in particular, reverse cholesterol transport. Apolipoprotein E (APOE) is the major apolipoprotein in the CNS, and in combination with high-density lipoprotein is mainly responsible for transporting cholesterol and amyloid around the brain. The APOE4 allele is associated with decreased APOE levels and is associated with AD. APOE is mostly synthesized by glial cells and can bind to the low-density lipoprotein receptor on neurons and thus be taken up. It has been suggested that APOE4 can result in excessive amyloid build up, interference with Tau metabolism, and/or disrupt lipid homeostasis and reduced neuronal plasticity; upregulating APOE levels might thus be protective. There is thus a close relationship between cholesterol transport and amyloid deposition-although the precise interrelationship needs to be clarified [244, 245]. Although an interesting effect, the possible influence of $\mathrm{CBD}$ on cholesterol efflux has not been further verified, and the precise molecular targets are not known; the concentrations required are also quite high.

\section{Pain}

The International Association for the Study of Pain defines pain as "an unpleasant sensory and emotional experience associated with actual or potential tissue damage, or described in terms of such damage". In many diseases such as MS or cancer, pain no longer serves its protective role, which is to avoid further tissue damage. Instead, because it is prolonged, it turns out to deteriorate the quality of life of individuals affected by these diseases. Although such chronic pain can be caused by either injury in the peripheral tissue or lesion in the CNS or in nerves, the common factor in both cases is inflammation. Current treatments are partially effective and are accompanied with side effects that can be more or less severe [246, 247]; therefore, new options of treatment involving cannabinoids (e.g., CBD) are now been pursued. In the present review, we are focusing on the mechanism of action underlying the therapeutic action of CBD only.

Although the effect of CBD on acute or chronic pain is still not well understood, a few studies using animal models of pain do suggest that CBD can be used to control inflammatory and neuropathic pain. It has been shown that a per os administration of CBD exerts antihyperalgesic effects on rat models of neuropathic and inflammatory pain [248, 249]. Microinjections of 3 $\mathrm{nM} \mathrm{CBD}$ in the ventrolateral periaqueductal gray appears to reduce the frequency of spikes generated by both $\mathrm{ON}$ cells and OFF cells (localized in the rostral ventromedial medulla (RVM), controlling the descending pathway of antinociception [250]. Furthermore, CBD appears to control allodynia and neuropathic pain caused by paclitaxel in mice $[251,252]$.

\section{CBD Ion Channel Targets in Pain}

TRP channels are currently seen as promising targets for pain management. A recent study suggests that each of them (e.g., TRPA1 and TRPV1) play distinct roles depending on the type of pain in rodent models [253]. So far, only TRPA1 and TRPV1 have been involved in the therapeutic action of CBD regarding the management of pain $[249,251]$. Capsazepine (intraperitoneally), a TRPV1 antagonist, abolished the therapeutic action of CBD in different rat models of pain such as carrageenaninduced thermal hyperalgesia, chronic constriction injury of 
the sciatic nerve, and the Freund's adjuvant model [248, 249]. As CBD may inhibit the cellular uptake of AEA, although at arguably supraphysiological concentrations, one could argue that TRPV1 is activated simultaneously by the excess of extracellular AEA and CBD - although such effects may only occur at supraphysiological concentrations. Interestingly, AM404, a blocker of AEA uptake, also exhibits analgesic characteristics in a rat model of neuropathic pain [254]. However, its beneficial effect is not prevented by capsazepine [249], indicating that the action of AEA upon TRPV1 is also involved in the management of neuropathic pain. Conversely, the action of CBD upon TRPV1 does not seem to regulate the descending pathway of antinociception. It appears that the reduction spikes frequency in both ON cells and OFF cells in the RVM caused by CBD is not reversed with 5'-iodo-resiniferatoxin, which antagonises TRPV1 [250]. On the contrary, it appears that the mechanism of action of CBD upon this descending pathway of antinociception may be mediated by TRPA1 [250]. Finally, although the inhibition of TRPM8 does not seem to be involved in the alleviation of inflammatory and neuropathic pain [255], it does appear that it attenuates cold hyperalgesia and tactile allodynia [253].

VGCCs present at nerve endings, such as Cav2.2, are involved in pain and appear to be important targets in the treatment of inflamed and neuropathic pain. A blockade of Cav2.2 using $\omega$-conotoxin MVIIA has been shown to alleviate both inflamed and neuropathic pain $[256,257]$. However, regarding other VGCCs such as Cav3.1, Cav3.2, and Cav3.3, which are targets for CBD [95], it is still not known whether they are channels that are important targets in the treatment of pain.

To date there has been no association between VDAC1 and pain. Therefore, it is not known whether the effect of CBD upon this protein is relevant to treat pain.

$\mathrm{CB}_{1} \mathrm{R}$ represent a useful target in the treatment of pain, although both the alleged antagonistic profile of CBD at $\mathrm{CB}_{1} \mathrm{R}$ at supraphysiological concentrations in vitro and absence of $\mathrm{CB}_{1} \mathrm{R}$-mediated effects in vivo indicate that any role of $\mathrm{CBD}$ in pain relief does not involve direct interaction with $\mathrm{CB}_{1} \mathrm{R}$ and $\mathrm{CB}_{2} \mathrm{R}[22,249,250,252]$.

\section{CBD Receptor Targets in Pain}

With regard to other receptor types, only 1 study has demonstrated that the mode of action of CBD upon the descending pathway of antinociception is dependent on the stimulation of $\mathrm{A}_{1}$ adenosine receptor [250]. 1, 3-Dipropyl-8cyclopentylxanthine, an $\mathrm{A}_{1}$ receptor antagonist, abolishes the effect of CBD on the spikes frequency generated by ON cells and OFF cells in the RVM, while blockade of this receptor reverses the beneficial effect of norisoboldine, which attenuates inflammatory pain [258]. To date, there is no evidence demonstrating a direct implication of adenosine $\mathrm{A}_{2}$ receptor in the therapeutic action of CBD in pain relief. Nevertheless, as
CBD suppresses the inflammatory response caused by adenosine $\mathrm{A}_{2}$ receptor, we can hypothesize that the inactivation of $\mathrm{A}_{2}$ adenosine receptor would promote pain. Interestingly, it has been shown that the knockout of adenosine $\mathrm{A}_{2 \mathrm{~A}}$ receptor in male and female mice protects against carrageenan-induced mechanical hyperalgesia [259].

The analgesic effect of CBD in a mice model of chronic pain is dependent on $\alpha 3$ GlyR [22], as, in a model of chronic pain, mice that do not express these GlyR were insensitive to the analgesic effect of CBD (50 mg/kg i.p.) [22].

It is still not clear whether CBD is able to manage paclitaxel-induced neuropathic pain through the activation of $5-\mathrm{HT}_{1 \mathrm{~A}}$ receptor or through the inhibition of $\mathrm{D}_{4}$ dopamine receptor [251, 252], as studies that often investigate the involvement of $5-\mathrm{HT}_{1 \mathrm{~A}}$ receptor in therapeutic action of $\mathrm{CBD}$ employ WAY-100635, which not only acts as an antagonist of $5-\mathrm{HT}_{1 \mathrm{~A}}$ receptor [260], but is also a potent agonist at the $\mathrm{D}_{4}$ dopamine receptor [48].

GPR55 has been implicated in inflammatory pain [261]. In fact, mice that do not express GPR55 do not exhibit inflammatory mechanical hyperalgesia for up to 14 days after the administration of Freund's complete adjuvant, although whether or not CBD mediates its action via GPR55 in vivo is unknown.

Although the activation of $\alpha-7$-nACh receptor has been reported as anti-inflammatory and protective against nociception in neuropathic pain [262-265], it is unlikely that the analgesic proprieties of CBD are mediated by this receptor as CBD tends to antagonize $\left(\mathrm{IC}_{50}=12.7 \mu \mathrm{M}\right)$ its action in vitro [27].

ORs exert analgesic effects [266]. However, their stimulation can be associated with several side effects, including addiction [267]. CBD has been described as a modulator of $\mu$ and $\delta$ ORs [28]; there are, however, no studies demonstrating this behaviorally. This might indicate that CBD can modulate the undesirable effect caused by opioids, such as addiction.

\section{CBD Enzyme Targets in Pain}

In addition, it is possible that $\mathrm{CBD}$ affects the metabolism of opioid analgesics by inhibiting CYP2D6, because polymorphism of CYP2D6 has been linked to distinct pain sensitivity and difference of response to opioid analgesics [268].

Among the targets of CBD, it appears that the TPRV1, TRPA1, and TRPM 8 may be of greater significance regarding the treatment of pain.

\section{Psychosis and Anxiety}

\section{CBD Ion Channel Targets in Psychosis}

CBD activates and rapidly desensitizes TRPV1 receptors at low micromolar concentrations. TRPV1 activation has been shown to cause anxiety-like behavior in rats. Current evidence 
indicates that $\mathrm{CBD}$ acts as an anxiolytic; therefore, $\mathrm{CBD}$ agonist activity at TRPV1 channels is not responsible for its anxiolytic effects [269]. A recent study indicates that the activation TRPV3 channels in rats reduced anxiety [270]. The TRPV3 receptor is not a plausible target for CBD, as high micromolar concentrations $(100 \mu \mathrm{M})$ are required for channel activation [71]. At present, neither TRPV2 nor TRPV4 have been reported to have any involvement in anxiety disorder or psychosis. Regarding other TRPV isoforms, no publications linking TRPA1 or TRPM8 to either disease have been made. CBD also binds VDAC1 and PPAR $\gamma$, but their roles in anxiety and psychosis have not been established.

At present there are no antianxiety drugs that target VGCCs, but CBD has been proven to act as a blocker of Cav3.1 and Cav3.2 T-type channels at low micromolar concentrations [271]. However, studies on mice indicate that Cav3.2 knockouts exhibit greater anxiety-like behavior [272]. Thus, blockade of Cav3.2 cannot explain the anxiolytic effects of CBD.

\section{CBD Receptor Targets in Psychosis}

$\mathrm{CBD}$ is a potent activator of the $5-\mathrm{HT}_{1 \mathrm{~A}}$ and $5-\mathrm{HT}_{2 \mathrm{~A}}$ receptors [26]. Buspirone activates the $5-\mathrm{HT}_{1 \mathrm{~A}}$ receptor to treat generalized anxiety disorder. Work undertaken recently shows that anxiety is greater in 5- $\mathrm{HT}_{1 \mathrm{~A}}$ knockout animals. However, 5$\mathrm{HT}_{2 \mathrm{~A}}$ knockouts produced the opposite outcome [169]. Based on the evidence so far, the $5-\mathrm{HT}_{1 \mathrm{~A}}$ receptor represents a good target for CBD in anxiety. It has been proposed that $5-\mathrm{HT}_{2 \mathrm{~A}}$ activation leads to psychotic symptoms. It is unlikely that $\mathrm{CBD}$ exerts its therapeutic effects through $5-\mathrm{HT}_{2 \mathrm{~A}}$ receptor activation, as CBD has never been shown to exert psychotropic effects. Thus, involvement of $5-\mathrm{HT}_{2 \mathrm{~A}}$ in the antipsychotic effect of CBD is unlikely [273].

As mentioned previously, GlyRs are mainly expressed in the brainstem and spinal cord, where they mediate inhibitory transmission. The activation of strychnine-sensitive GlyRs by taurine reduced anxiety in rodent models [274]. High micromolar concentrations of CBD are required to activate GlyRs and therefore GlyRs are not appropriate targets for CBD.

The roles of the $\mu$ and $\delta$ ORs has been studied in rodent models of anxiety. $\mu \mathrm{OR}$ activation has been associated with anxiogenic effects, while $\delta$ OR activation reduced anxiety-like behavior [275]. Although their role in anxiety has been established, the high micromolar concentrations of CBD required for OR activation are not achievable in vivo [28]. Therefore, it is unlikely that CBD effects at ORs mediate anxiety, and no reports linking opioid transmission to psychosis have been made so far.

The GPR55 receptor is expressed in the hippocampus, where they trigger $\mathrm{Ca}^{2+}$ release from the sarcoplasmic reticulum upon activation [276]. It has been demonstrated that GPR55 activation produces anxiolytic effects in rodent models; therefore, the antagonistic properties of CBD at GPR55 are not consistent with its antianxiety response. It is not known if GPR55 is involved in psychosis.

In vitro studies have shown that $\mathrm{A}_{1}$ and $\mathrm{A}_{2}$ receptors are potently activated by $\mathrm{CBD}$. In zebrafish, the $\mathrm{A}_{1}$ receptor subtype has been implicated in anxiety, where its blockade caused anxiety-like behaviors. Current pharmacological data do not support the involvement of $\mathrm{A}_{2}$ receptors in anxiety [277], or either receptor isoform in psychosis, but blockade of adenosine clearance produced antipsychotic effects in rats [278]. Adenosine agonists cannot be used as treatments, as they reduce cardiac output [170]. This effect was not observed when CBD was administered to either humans or animals; therefore, it is likely that CBD causes an indirect elevation of adenosine release as opposed to receptor activation.

\section{CBD Enzyme Targets in Psychosis}

Although CYP enzymes are present in the CNS, it is not known if they are involved in anxiety or psychosis. AANAT has not been implicated in either disease. An increased expression of COX2 has been reported in patients with schizophrenia [279]. A very high concentration of CBD is required to interact with these enzymes, so it is unlikely they are involved in the anxiolytic or antipsychotic effect of CBD.

An elevation in FAAH activity has been reported following chronic restraint stress in animal models, and also anxiety-like behaviors [280]. FAAH inhibition also alleviates psychotic symptoms in patients with schizophrenia [281]. CBD is a potent inhibitor of FAAH; therefore, it is worth investigating if this will provide a therapeutic effect.

\section{CBD Transporter Targets in Psychosis}

The inhibition of glutamate uptake by CBD is not consistent with its anxiolytic effects, as blockade of the glutamate transporter has been shown to create anxiety-like behaviors in rodents. It has been proposed that patients with reduced levels of glutamate in the thalamus are at greater risk of psychosis, thus blockade of glutamate uptake will not treat psychosis in patients [167]. Elevated levels of adenosine lead to greater activation of the $A_{1}$ receptor, which has been linked to anxiolytic effects. Thus, inhibition of ENT1, responsible for adenosine uptake, may provide a therapeutic effect. Dopamine uptake has not been implicated in anxiety or psychosis [282].

CBD inhibits AEA uptake at likely supraphysiological concentrations, possibly by binding an unknown AEA transporter [19, 71]. Although the inhibition of AEA uptake has produced anxiolytic responses in animal models, previous studies have shown that $\mathrm{CB}_{1} \mathrm{R}$ activation leads to psychotropic effects; this has never been observed following CBD treatment [279]. Furthermore, prolonged $\mathrm{CB}_{1} \mathrm{R}$ activation leads to tolerance, which has not been reported in CBD-treated 
animals [180]. Thus, it is unlikely that the AEA transporter is involved in the anxiolytic or antipsychotic effect of CBD.

\section{Addiction}

The therapeutic effect of CBD on addiction has not yet been well established. So far, only 2 studies have approached this question directly [283, 284]. Preliminary studies performed on rats trained to self-administer heroin for 6 sessions showed that CBD (5 mg/kg and $20 \mathrm{mg} / \mathrm{kg}$ i.p.) did not reduce heroin self-administration behavior. However, when CBD is administered $24 \mathrm{~h}$ before the test, it attenuates conditioned cueinduced heroin-seeking behavior after a 2 -week period of abstinence [284]. Conversely, the same treatment ( $24 \mathrm{~h}$ prior to test) did not significantly reduce drug-seeking behavior after heroin prime. Furthermore, the authors showed that CBD promotes the extinction of heroin self-administration [284]. Another study recently performed on 24 tobacco smokers suggested that CBD could reduce $(\sim 40 \%)$ the number of cigarettes smoked [283], but the effect did not persist after treatment nor did it alter craving.

\section{CBD Ion Channel Targets in Addiction}

If $\mathrm{CBD}$ did exert antiaddictive proprieties, the evidence so far would suggest that molecular targets involved in the metabolism of drug such as CYP450, the transporter of drugs (e.g., ABCG2) and ORs, would be of greatest interest.

Its action upon TRPV1 may not mediate any therapeutic effects in addiction, AS blocking this channel turns out to be beneficial to control addictive behavior [285, 286]. Equally, the roles of VDAC1, VGCCs, and the other TRP channels that are targets for CBD have not yet had their role in addiction

Table 5 Most plausible molecular targets of cannabidiol (CBD) warranting further investigation in specific disease stated

\begin{tabular}{|c|c|}
\hline Disease or disease group & Most plausible molecular targets of CBD \\
\hline Epilepsy & $\begin{array}{l}\text { VDAC1, CaV3.x, 5-HT } 1 \mathrm{~A}, \text { GlyR, GPR55, } \\
\text { adenosine modulation (ENT1) }\end{array}$ \\
\hline Movement disorders & $\mathrm{CaV} 3 . \mathrm{x}, 5-\mathrm{HT}_{1 \mathrm{~A}}, \mathrm{VDAC1}$ \\
\hline Neurodegenerative diseases & VDAC1, FABP, GPR55, NRF2, ENT1 \\
\hline Pain & TRPV1, TRPA1, TRPM8 \\
\hline Psychosis and anxiety & $5-\mathrm{HT}_{1 \mathrm{~A}}$, adenosine modulation (ENT1) \\
\hline Addiction & CYP2D6, opioid receptors, ABCG2 \\
\hline
\end{tabular}

VDAC1 $=$ voltage-dependent anion channel $1 ; 5-\mathrm{HT}=$ serotonin $;$ GlyR = glycine receptor; GPR55 = G protein-coupled receptor 55; ENT1 $=$ equilibrative nucleoside transporter $1 ; \mathrm{FABP}=$ fatty acid binding protein; NRF2 $=$ Nuclear factor erythroid 2-related factor 2; TRPV1 = transient receptor potential vanilloid-type 1 ; TRPA $1=$ transient receptor potential ankyrin type 1 ; TRPM8 = transient receptor potential subfamily M; CYP $=$ cytochrome $\mathrm{P}$ firmly established. Although, it has been shown that opiates are involved in the internalization of TRPM8, which can affect thermosensitization and pain [287], it remains unclear whether this plays any role in addiction.

\section{CBD Enzyme Targets in Addiction}

A reduced activity of CYP2D6 has been associated with protection against addictive behavior caused by oral opiate [288]. Interestingly, CYP2D6 is highly expressed in the brain of alcoholics [289]. This may indicate that the activity of CYP2D6 is of great importance in the pathway of addiction associated with drugs. For further details about the opioid system and CBD see the section on pain.

\section{CBD Transporter Targets in Addiction}

Finally, it is possible that the effect of CBD upon ABCG2 may impact drugs transport and drug abuse [290].

\section{Conclusions}

We have identified a large number of potential molecular targets of CBD which are likely to be of direct relevance to many of the therapeutic effects of this compound reported in large number of preclinical and smaller numbers of clinical studies. However, despite such an extensive literature, there is a paucity of studies that incontrovertibly demonstrate which specific molecular targets underlying different therapeutic effects of CBD. A significant area of confusion in this regard has been the assumption that, being a cannabinoid, CBD acts through the ECS; an assumption that has now been largely dismissed. Moreover, the lipophilic nature of CBD and the membranebound nature of many of the targets implicated means that many of the effects reported at high micromolar (or higher) concentrations in vitro are likely to be nonspecific and of dubious relevance to any therapeutic effect. Thus, considerable caution should be exercised when both interpreting the extant literature and designing new studies to determine CBD mechanisms of action. While definitive statements regarding the specific molecular targets underlying CBD's effects cannot yet be made, our review of the literature has identified several targets per therapeutic indication which, on the balance of evidence, warrant further, focused investigation in studies that establish causal relationships between target and effect (Table 5).

Required Author Forms Disclosure forms provided by the authors are available with the online version of this article. 


\section{References}

1. Brunner TF. Marijuana in ancient Greece and Rome? The literary evidence. Bull Hist Med 1973;47:344-355.

2. Dark P. The environment of Britain in the first millennium AD. UK: Bloomsbury Academic Press, 2000.

3. Li H-L. An archaeological and historical account of cannabis in China. Econ Bot 1973;28:437-448.

4. Manniche L. An ancient Egyptian herbal. British Museum Press.

5. Mathre ML. Cannabis in medical practice: a legal, historical and pharmacological overview of the therapeutic use of marijuana. McFarland \& Co Inc., Jefferson, NC. USA, 1997.

6. Mikuriya TH. Marijuana in medicine: past, present and future. Calif Med 1969;110:34-40.

7. Morningstar PJ. Thandai and chilam: traditional Hindu beliefs about the proper uses of Cannabis. J Psychoactive Drugs 1985; 17:141-165.

8. Pollington S. Leechcraft: early English charms, plant lore, and healing. Anglo-Saxon Books. UK, 2000.

9. Touw M. The religious and medicinal uses of Cannabis in China, India and Tibet. J Psychoactive Drugs 1981;13:23-34.

10. Mecha M, Feliú A, Iñigo PM, Mestre L, Carrillo-Salinas FJ, Guaza C. Cannabidiol provides long-lasting protection against the deleterious effects of inflammation in a viral model of multiple sclerosis: a role for A2A receptors. Neurobiol Dis 2013;59:141150.

11. Serpell M, Ratcliffe S, Hovorka J, et al. A double-blind, randomized, placebo-controlled, parallel group study of THC/CBD spray in peripheral neuropathic pain treatment. Eur J Pain 2014;18:9991012.

12. Shrivastava A, Kuzontkoski PM, Groopman JE, Prasad A. Cannabidiol induces programmed cell death in breast cancer cells by coordinating the cross-talk between apoptosis and autophagy. Mol Cancer Ther 2011;10:1161-1172.

13. Pertwee R. Handbook of cannabis. Oxford University Press.

14. Porter BE, Jacobson C. Report of a parent survey of cannabidiolenriched cannabis use in pediatric treatment-resistant epilepsy. Epilepsy Behav 2013;29:574-577.

15. GW Pharma. GW Pharmaceuticals provides update on Epidiolex ${ }^{\circledR}$ program in treatment-resistant childhood epilepsies. Available at: http://www.gwpharm.com/GW\%20 Pharmaceuticals\% 20Provides\%20Update $\% 20$ on $\% 20$ Epidiolex $\% 20$ Program $\%$ 20in\%20Treatment-Resistant $\% 20$ Childhood\%20Epilepsies.aspx. Accessed August 4, 2015.

16. McPartland JM, Duncan M, Di Marzo V, Pertwee RG. Are cannabidiol and $\Delta(9)$-tetrahydrocannabivarin negative modulators of the endocannabinoid system? A systematic review. Br J Pharmacol 2015;172:737-753.

17. Deiana S, Watanabe A, Yamasaki Y, et al. Plasma and brain pharmacokinetic profile of cannabidiol (CBD), cannabidivarine (CBDV), $\Delta^{9}$-tetrahydrocannabivarin (THCV) and cannabigerol $(\mathrm{CBG})$ in rats and mice following oral and intraperitoneal administration and $\mathrm{CBD}$ action on obsessive-compulsive behaviour. Psychopharmacology (Berl) 2012;219:859-873.

18. Ramer R, Heinemann K, Merkord J, et al. COX-2 and PPAR- $\gamma$ confer cannabidiol-induced apoptosis of human lung cancer cells. Mol Cancer Ther 2013;12:69-82.

19. Bisogno T, Hanus L, De Petrocellis L, et al. Molecular targets for cannabidiol and its synthetic analogues: effect on vanilloid VR1 receptors and on the cellular uptake and enzymatic hydrolysis of anandamide. Br J Pharmacol 2001;134:845-852.

20. Ryberg E, Larsson N, Sjögren S, et al. The orphan receptor GPR55 is a novel cannabinoid receptor. Br J Pharmacol 2007;152:1092-1101.
21. Ahrens J, Demir R, Leuwer M, et al. The nonpsychotropic cannabinoid cannabidiol modulates and directly activates alpha-1 and alpha-1-Beta glycine receptor function. Pharmacology 2009;83: 217-222.

22. Xiong W, Cui T, Cheng K, et al. Cannabinoids suppress inflammatory and neuropathic pain by targeting $\alpha 3$ glycine receptors. J Exp Med 2012;209:1121-1134.

23. McHugh D. GPR18 in microglia: implications for the CNS and endocannabinoid system signalling. Br J Pharmacol 2012;167: 1575-1582.

24. Whyte LS, Ryberg E, Sims NA, et al. The putative cannabinoid receptor GPR55 affects osteoclast function in vitro and bone mass in vivo. Proc Natl Acad Sci U S A 2009;106:16511-16516.

25. Li K, Fichna J, Schicho R, et al. A role for O-1602 and G proteincoupled receptor GPR55 in the control of colonic motility in mice. Neuropharmacology 2013;71:255-263.

26. Russo EB, Burnett A, Hall B, Parker KK. Agonistic properties of cannabidiol at 5-HT1a receptors. Neurochem Res 2005;30:10371043.

27. Mahgoub M, Keun-Hang SY, Sydorenko V, et al. Effects of cannabidiol on the function of $\alpha 7$-nicotinic acetylcholine receptors. Eur J Pharmacol 2013;720:310-319.

28. Kathmann M, Flau K, Redmer A, Tränkle C, Schlicker E. Cannabidiol is an allosteric modulator at mu- and delta-opioid receptors. Naunyn. Schmiedebergs Arch Pharmacol 2006;372: 354-361.

29. Pertwee RG. The diverse CB1 and CB2 receptor pharmacology of three plant cannabinoids: delta9-tetrahydrocannabinol, cannabidiol and delta9-tetrahydrocannabivarin. Br J Pharmacol 2008;153:199-215.

30. Thomas A, Baillie GL, Phillips AM, Razdan RK, Ross RA, Pertwee RG. Cannabidiol displays unexpectedly high potency as an antagonist of $\mathrm{CB} 1$ and $\mathrm{CB} 2$ receptor agonists in vitro. Br J Pharmacol 2007;150:613-623.

31. Castillo A, Tolón MR, Fernández-Ruiz J, Romero J, MartinezOrgado J. The neuroprotective effect of cannabidiol in an in vitro model of newborn hypoxic-ischemic brain damage in mice is mediated by $\mathrm{CB}(2)$ and adenosine receptors. Neurobiol Dis 2010;37:434-440.

32. Járai Z, Wagner JA, Varga $\mathrm{K}$, et al. Cannabinoid-induced mesenteric vasodilation through an endothelial site distinct from $\mathrm{CB} 1$ or CB2 receptors. Proc Natl Acad Sci U S A 1999;96:14136-14141.

33. Schmuhl E, Ramer R, Salamon A, Peters K, Hinz B. Increase of mesenchymal stem cell migration by cannabidiol via activation of p42/44 MAPK. Biochem Pharmacol 2014;87:489-501.

34. Yang J-N, Chen J-F, Fredholm BB. Physiological roles of A1 and $\mathrm{A} 2 \mathrm{~A}$ adenosine receptors in regulating heart rate, body temperature, and locomotion as revealed using knockout mice and caffeine. Am J Physiol Heart Circ Physiol 2009;296:H1141-H1149.

35. Elmenhorst D, Meyer PT, Winz OH, et al. Sleep deprivation increases A1 adenosine receptor binding in the human brain: a positron emission tomography study. J. Neurosci. Off J Soc Neurosci 2007;27:2410-2415.

36. Gonca E, Darıc1 F. The effect of cannabidiol on ischemia/ reperfusion-induced ventricular arrhythmias: the role of adenosine A1 receptors. J Cardiovasc Pharmacol Ther 2015;20:76-83.

37. Liou GI, Auchampach JA, Hillard CJ, et al. Mediation of cannabidiol anti-inflammation in the retina by equilibrative nucleoside transporter and $\mathrm{A} 2 \mathrm{~A}$ adenosine receptor. Invest Ophthalmol Vis Sci 2008;49:5526-5531.

38. Sagredo O, Ramos JA, Decio A, Mechoulam R, Fernández-Ruiz J. Cannabidiol reduced the striatal atrophy caused 3-nitropropionic acid in vivo by mechanisms independent of the activation of cannabinoid, vanilloid TRPV1 and adenosine A2A receptors. Eur J Neurosci 2007;26:843-851. 
39. Lynch JW. Molecular structure and function of the glycine receptor chloride channel. Physiol Rev 2004;84:1051-1095.

40. Xiong W, Chen S-R, He L, et al. Presynaptic glycine receptors as a potential therapeutic target for hyperekplexia disease. Nat Neurosci 2014; 17:232-239.

41. Madar I, Lesser RP, Krauss G, et al. Imaging of delta- and muopioid receptors in temporal lobe epilepsy by positron emission tomography. Ann Neurol 1997;41:358-367.

42. Resstel LBM, Tavares RF, Lisboa SFS, Joca SRL, Corrêa FMA, Guimarães FS. 5-HT1A receptors are involved in the cannabidiolinduced attenuation of behavioural and cardiovascular responses to acute restraint stress in rats. Br J Pharmacol 2009;156:181-188.

43. Soares V de P, Campos AC, Bortoli VC de, Zangrossi H Jr, Guimarães FS, Zuardi AW. Intra-dorsal periaqueductal gray administration of cannabidiol blocks panic-like response by activating 5-HT1A receptors. Behav Brain Res 2010;213:225-229.

44. Yang K-H, Galadari S, Isaev D, Petroianu G, Shippenberg TS, Oz $\mathrm{M}$. The nonpsychoactive cannabinoid cannabidiol inhibits 5hydroxytryptamine3A receptor-mediated currents in Xenopus laevis oocytes. J Pharmacol Exp Ther 2010;333:547-554.

45. Zanelati TV, Biojone C, Moreira FA, Guimarães FS, Joca SRL. Antidepressant-like effects of cannabidiol in mice: possible involvement of 5-HT1A receptors. Br J Pharmacol 2010;159:122128

46. Saigal N, Bajwa AK, Faheem SS, et al. Evaluation of serotonin 5HT1A receptors in rodent models using [18F]Mefway PET. Synapse 2013;67:596-608.

47. Austgen JR, Kline DD. Endocannabinoids blunt the augmentation of synaptic transmission by serotonin $2 \mathrm{~A}$ receptors in the nucleus tractus solitarii (nTS). Brain Res 2013;1537:27-36.

48. Chemel BR, Roth BL, Armbruster B, Watts VJ, Nichols DE. WAY-100635 is a potent dopamine D4 receptor agonist. Psychopharmacology (Berl) 2006;188:244-251.

49. Alves FHF, Crestani CC, Gomes FV, Guimarães FS, Correa FMA, Resstel LBM. Cannabidiol injected into the bed nucleus of the stria terminalis modulates baroreflex activity through 5-HT1A receptors. Pharmacol Res 2010;62:228-236.

50. Gomes FV, Alves FHF, Guimarães FS, Correa FMA, Resstel LBM, Crestani CC. Cannabidiol administration into the bed nucleus of the stria terminalis alters cardiovascular responses induced by acute restraint stress through 5-HT1A receptor. Eur. Neuropsychopharmacol 2013;23:1096-1104.

51. Sylantyev S, Jensen TP, Ross RA, Rusakov DA. Cannabinoidand lysophosphatidylinositol-sensitive receptor GPR55 boosts neurotransmitter release at central synapses. Proc Natl Acad Sci U S A 2013;110:5193-5198.

52. Baker D, Pryce G, Davies WL, Hiley CR. In silico patent searching reveals a new cannabinoid receptor. Trends Pharmacol Sci 2006;27:1-4

53. Oka S, Nakajima K, Yamashita A, Kishimoto S, Sugiura T. Identification of GPR55 as a lysophosphatidylinositol receptor. Biochem Biophys Res Commun 2007;362:928-934.

54. O'Sullivan SE, Sun Y, Bennett AJ, Randall MD, Kendall DA. Time-dependent vascular actions of cannabidiol in the rat aorta. Eur J Pharmacol 2009;612:61-68.

55. Usami N, Yamamoto I, Watanabe K. Generation of reactive oxygen species during mouse hepatic microsomal metabolism of cannabidiol and cannabidiol hydroxy-quinone. Life Sci 2008;83: 717-724.

56. Zhou S-F, Liu J-P, Chowbay B. Polymorphism of human cytochrome P450 enzymes and its clinical impact. Drug Metab Rev 2009;41:89-295

57. Jiang R, Yamaori S, Okamoto Y, Yamamoto I, Watanabe K. Cannabidiol is a potent inhibitor of the catalytic activity of cytochrome P450 2C19. Drug Metab Pharmacokinet 2013;28:332-338.
58. Booth Depaz IM, Toselli F, Wilce PA, Gillam EMJ. Differential expression of cytochrome P450 enzymes from the CYP2C subfamily in the human brain. Drug Metab Dispos Biol Fate Chem 2015;43:353-357.

59. Wu M, Chen S, Wu X. Differences in cytochrome P450 2C19 (CYP2C19) expression in adjacent normal and tumor tissues in Chinese cancer patients. Med Sci Monit 2006;12:BR174-BR178.

60. Yamaori S, Okamoto Y, Yamamoto I, Watanabe K. Cannabidiol, a major phytocannabinoid, as a potent atypical inhibitor for CYP2D6. Drug Metab Dispos 2011;39:2049-2056.

61. Yamaori S, Koeda K, Kushihara M, Hada Y, Yamamoto I, Watanabe K. Comparison in the in vitro inhibitory effects of major phytocannabinoids and polycyclic aromatic hydrocarbons contained in marijuana smoke on cytochrome P450 2C9 activity. Drug Metab Pharmacokinet 2012;27:294-300.

62. Yamaori S, Kushihara M, Yamamoto I, Watanabe K. Characterization of major phytocannabinoids, cannabidiol and cannabinol, as isoform-selective and potent inhibitors of human CYP1 enzymes. Biochem Pharmacol 2010;79:1691-1698.

63. Yamaori S, Ebisawa J, Okushima Y, Yamamoto I, Watanabe K. Potent inhibition of human cytochrome P450 3A isoforms by cannabidiol: role of phenolic hydroxyl groups in the resorcinol moiety. Life Sci 2011;88:730-736.

64. Cornicelli JA, Gilman SR, Krom BA, Kottke BA. Cannabinoids impair the formation of cholesteryl ester in cultured human cells. Arteriosclerosis 1981;1:449-454.

65. Koch M, Dehghani F, Habazettl I, Schomerus C, Korf H-W. Cannabinoids attenuate norepinephrine-induced melatonin biosynthesis in the rat pineal gland by reducing arylalkylamine Nacetyltransferase activity without involvement of cannabinoid receptors. J Neurochem 2006;98:267-278.

66. Fišar Z, Singh N, Hroudová J. Cannabinoid-induced changes in respiration of brain mitochondria. Toxicol Lett 2014;231:62-71.

67. Valvassori SS, Bavaresco DV, Scaini G, et al. Acute and chronic administration of cannabidiol increases mitochondrial complex and creatine kinase activity in the rat brain. Rev Bras Psiquiatr 2013;35:380-386.

68. Massi P, Valenti M, Vaccani A, et al. 5-Lipoxygenase and anandamide hydrolase (FAAH) mediate the antitumor activity of cannabidiol, a non-psychoactive cannabinoid. J Neurochem 2008;104:1091-1100.

69. Ruhaak LR, Felth J, Karlsson PC, Rafter JJ, Verpoorte R, Bohlin L. Evaluation of the cyclooxygenase inhibiting effects of six major cannabinoids isolated from Cannabis sativa. Biol Pharm Bull 2011;34:774-778.

70. Yamaori S, Okushima Y, Masuda K, et al. Structural requirements for potent direct inhibition of human cytochrome P450 1A1 by cannabidiol: role of pentylresorcinol moiety. Biol Pharm Bull 2013;36:1197-1203.

71. De Petrocellis L, Ligresti A, Moriello AS, et al. Effects of cannabinoids and cannabinoid-enriched Cannabis extracts on TRP channels and endocannabinoid metabolic enzymes. Br J Pharmacol 2011;163:1479-1494.

72. Jenny M, Santer E, Pirich E, Schennach H, Fuchs D. Delta9tetrahydrocannabinol and cannabidiol modulate mitogen-induced tryptophan degradation and neopterin formation in peripheral blood mononuclear cells in vitro. J Neuroimmunol 2009;207:7582.

73. Takeda S, Usami N, Yamamoto I, Watanabe K. Cannabidiol-2',6'dimethyl ether, a cannabidiol derivative, is a highly potent and selective 15-lipoxygenase inhibitor. Drug Metab Dispos Biol Fate Chem 2009;37:1733-1737.

74. Evans AT, Formukong E, Evans FJ. Activation of phospholipase A2 by cannabinoids. Lack of correlation with CNS effects. FEBS Lett 1987;211:119-122. 
75. Watanabe K, Motoya E, Matsuzawa N, et al. Marijuana extracts possess the effects like the endocrine disrupting chemicals. Toxicology 2005;206:471-478.

76. Burstein S, Hunter SA, Renzulli L. Stimulation of sphingomyelin hydrolysis by cannabidiol in fibroblasts from a Niemann-Pick patient. Biochem Biophys Res Commun 1984;121:168-173.

77. Jiang R, Yamaori S, Takeda S, Yamamoto I, Watanabe K. Identification of cytochrome P450 enzymes responsible for metabolism of cannabidiol by human liver microsomes. Life Sci 2011;89:165-170.

78. Bryan HK, Olayanju A, Goldring CE, Park BK. The Nrf2 cell defence pathway: Keap1-dependent and -independent mechanisms of regulation. Biochem. Pharmacol 2013;85:705-717.

79. Juknat A, Pietr M, Kozela E, et al. Microarray and pathway analysis reveal distinct mechanisms underlying cannabinoid-mediated modulation of LPS-induced activation of BV-2 microglial cells. PloS One 2013;8:e61462.

80. Bock J, Szabó I, Gamper N, Adams C, Gulbins E. Ceramide inhibits the potassium channel Kv1.3 by the formation of membrane platforms. Biochem. Biophys Res Commun 2003;305:890897.

81. Cremesti AE, Goni FM, Kolesnick R. Role of sphingomyelinase and ceramide in modulating rafts: do biophysical properties determine biologic outcome? FEBS Lett 2002;531:47-53.

82. Maziere JC, Maziere C, Mora L, Routier JD, Polonovski J. In situ degradation of sphingomyelin by cultured normal fibroblasts and fibroblasts from patients with Niemann-Pick disease type A and C. Biochem Biophys Res Commun 1982;108:1101-1106.

83. Massi P, Vaccani A, Ceruti S, Colombo A, Abbracchio MP, Parolaro D. Antitumor effects of cannabidiol, a nonpsychoactive cannabinoid, on human glioma cell lines. J Pharmacol Exp Ther 2004;308:838-845.

84. Rimmerman N, Ben-Hail D, Porat Z, et al. Direct modulation of the outer mitochondrial membrane channel, voltage-dependent anion channel 1 (VDAC1) by cannabidiol: a novel mechanism for cannabinoid-induced cell death. Cell Death Dis 2013;4:e949.

85. Shoshan-Barmatz V, Mizrachi D. VDAC1: from structure to cancer therapy. Mol Cell Oncol 2012;2:164.

86. Singh N, Hroudová J, Fišar Z. Cannabinoid-induced changes in the activity of electron transport chain complexes of brain mitochondria. J Mol Neurosci 2015 Mar 29 [Epub ahead of print].

87. Escames G, León J, López LC, Acuña-Castroviejo D. Mechanisms of N-methyl-D-aspartate receptor inhibition by melatonin in the rat striatum. J Neuroendocrinol 2004;16:929-935.

88. Ozkanlar S, Kara A, Sengul E, Simsek N, Karadeniz A, Kurt N. Melatonin modulates the immune system response and inflammation in diabetic rats experimentally-induced by alloxan. Horm Metab Res 2015 May 4 [Epub ahead of print].

89. Ramis MR, Esteban S, Miralles A, Tan D-X, Reiter RJ. Protective effects of melatonin and mitochondria-targeted antioxidants against oxidative stress: a review. Curr Med Chem 2015 Jun 18 [Epub ahead of print].

90. Sun GY, Shelat PB, Jensen MB, He Y, Sun AY, Simonyi A. Phospholipases A2 and inflammatory responses in the central nervous system. Neuromolecular Med 2010;12:133-148.

91. Arriagada E, Cid H. Search for a "toxic site" in snake venom phospholipases A2. Arch Biol Med Exp 1989;22:97-105.

92. Calder PC. Omega-3 fatty acids and inflammatory processes. Nutrients 2010;2:355-374.

93. Wheal AJ, Cipriano M, Fowler CJ, Randall MD, O’Sullivan SE. Cannabidiol improves vasorelaxation in Zucker diabetic fatty rats through cyclooxygenase activation. J Pharmacol Exp Ther 2014;351:457-466.

94. Hoyo-Becerra C, Schlaak JF, Hermann DM. Insights from interferon- $\alpha$-related depression for the pathogenesis of depression associated with inflammation. Brain Behav Immun 2014;42:222231.

95. Ross HR, Napier I, Connor M. Inhibition of recombinant human T-type calcium channels by Delta9-tetrahydrocannabinol and cannabidiol. J Biol Chem 2008;283:16124-16134.

96. Qin N, Neeper MP, Liu Y, Hutchinson TL, Lubin ML, Flores CM. TRPV2 is activated by cannabidiol and mediates CGRP release in cultured rat dorsal root ganglion neurons. J Neurosci 2008;28: 6231-6238.

97. De Petrocellis L, Vellani V, Schiano-Moriello A, et al. Plantderived cannabinoids modulate the activity of transient receptor potential channels of ankyrin type-1 and melastatin type-8. J Pharmacol Exp Ther 2008;325:1007-1015.

98. Iannotti FA, Hill CL, Leo A, et al. Nonpsychotropic plant cannabinoids, cannabidivarin (CBDV) and cannabidiol (CBD), activate and desensitize transient receptor potential vanilloid 1 (TRPV1) channels in vitro: potential for the treatment of neuronal hyperexcitability. ACS Chem Neurosci 2014;5:1131-1141

99. Ligresti A, Moriello AS, Starowicz K, et al. Antitumor activity of plant cannabinoids with emphasis on the effect of cannabidiol on human breast carcinoma. J Pharmacol Exp Ther 2006;318:13751387.

100. Nabissi M, Morelli MB, Santoni M, Santoni G. Triggering of the TRPV2 channel by cannabidiol sensitizes glioblastoma cells to cytotoxic chemotherapeutic agents. Carcinogenesis 2013;34:4857.

101. De Petrocellis L, Orlando P, Moriello AS, et al. Cannabinoid actions at TRPV channels: effects on TRPV3 and TRPV4 and their potential relevance to gastrointestinal inflammation. Acta Physiol 2012;204:255-266.

102. Billeter AT, Hellmann JL, Bhatnagar A, Polk HC. Transient receptor potential ion channels: powerful regulators of cell function. Ann Surg 2014;259:229-235.

103. Holland ML, Allen JD, Arnold JC. Interaction of plant cannabinoids with the multidrug transporter ABCC1 (MRP1). Eur J Pharmacol 2008;591:128-131.

104. Holland ML, Lau DTT, Allen JD, Arnold JC. The multidrug transporter ABCG2 (BCRP) is inhibited by plant-derived cannabinoids. Br J Pharmacol 2007;152:815-824.

105. Pandolfo P, Silveirinha V, Santos-Rodrigues A dos, et al. Cannabinoids inhibit the synaptic uptake of adenosine and dopamine in the rat and mouse striatum. Eur J Pharmacol 2011;655:3845.

106. Carrier EJ, Auchampach JA, Hillard CJ. Inhibition of an equilibrative nucleoside transporter by cannabidiol: a mechanism of cannabinoid immunosuppression. Proc Natl Acad Sci U S A 2006;103:7895-7900.

107. Gilbert JC, Pertwee RG, Wyllie MG. Effects of delta9tetrahydrocannabinol and cannabidiol on a Mg2+-ATPase of synaptic vesicles prepared from rat cerebral cortex. Br J Pharmacol 1977;59:599-601.

108. Coyle JT, and Snyder SHJ. Catecholamine uptake by synaptosomes in homogenates of rat brain: Stereospecificity in different areas. Pharmacol Exp Ther 1969;170:221.

109. Whittaker VP, Michaelson IA, Kirkland RJA. The separation of synaptic vesicles from nerve-ending particles ('synaptosomes'). Biochem J 1964;90:293-303.

110. Di Marzo V, Fontana A, Cadas H, et al. Formation and inactivation of endogenous cannabinoid anandamide in central neurons. Nature 1994;372:686-691

111. Morelli MB, Offidani M, Alesiani F, et al. The effects of cannabidiol and its synergism with bortezomib in multiple myeloma cell lines. A role for transient receptor potential vanilloid type-2. Int J Cancer 2014;134:2534-2546. 
112. Shoshan-Barmatz V, De Pinto V, Zweckstetter M, Raviv Z, Keinan $\mathrm{N}$, Arbel N. VDAC, a multi-functional mitochondrial protein regulating cell life and death. Mol Aspects Med 2010;31:227-285.

113. Hill AJ, Jones NA, Smith I, et al. Voltage-gated sodium (NaV) channel blockade by plant cannabinoids does not confer anticonvulsant effects per se. Neurosci Lett 2014;566:269-274.

114. Vandenberg RJ, Ryan RM. Mechanisms of glutamate transport. Physiol Rev 2013;93:1621-1657.

115. Banerjee SP, Snyder SH, Mechoulam R. Cannabinoids: influence on neurotransmitter uptake in rat brain synaptosomes. J Pharmacol Exp Ther 1975;194:74-81.

116. Poddar MK, Dewey WL. Effects of cannabinoids on catecholamine uptake and release in hypothalamic and striatal synaptosomes. J Pharmacol Exp Ther 1980;214:63-67.

117. Lindamood C 3rd, Colasanti BK. Effects of delta 9tetrahydrocannabinol and cannabidiol on sodium-dependent high affinity choline uptake in the rat hippocampus. J Pharmacol Exp Ther 1980;213:216-221

118. Rakhshan F, Day TA, Blakely RD, Barker EL. Carrier-mediated uptake of the endogenous cannabinoid anandamide in RBL-2H3 cells. J Pharmacol Exp Ther 2000;292:960-967.

119. Watanabe K, Kayano Y, Matsunaga T, Yamamoto I, Yoshimura H. Inhibition of anandamide amidase activity in mouse brain microsomes by cannabinoids. Biol Pharm Bull 1996;19:1109-1111.

120. Di Marzo V, Melck D, De Petrocellis L, Bisogno T. Cannabimimetic fatty acid derivatives in cancer and inflammation. Prostaglandins Other Lipid Mediat 2000;61:43-61.

121. Zhu H-J, Wang J-S, Markowitz JS, et al. Characterization of Pglycoprotein inhibition by major cannabinoids from marijuana. $\mathrm{J}$ Pharmacol Exp Ther 2006;317:850-857.

122. Szemraj J, Sobolewska B, Gulczynska E, Wilczynski J, Zylinska L. Magnesium sulfate effect on erythrocyte membranes of asphyxiated newborns. Clin Biochem 2005;38:457-464.

123. Schmidt D, Schachter SC. Drug treatment of epilepsy in adults. BMJ 2014;348:g254

124. Devinsky O, Cilio MR, Cross H, et al. Cannabidiol: pharmacology and potential therapeutic role in epilepsy and other neuropsychiatric disorders. Epilepsia 2014;55:791-802.

125. Shu H-F, Yu S-X, Zhang C-Q, et al. Expression of TRPV1 in cortical lesions from patients with tuberous sclerosis complex and focal cortical dysplasia type IIb. Brain Dev 2013;35:252-260.

126. Rüden EL von, Jafari M, Bogdanovic RM, Wotjak CT, Potschka $\mathrm{H}$. Analysis in conditional cannabinoid 1 receptor-knockout mice reveals neuronal subpopulation-specific effects on epileptogenesis in the kindling paradigm. Neurobiol Dis 2015;73:334-347.

127. Samineni VK, Premkumar LS, Faingold CL. Post-ictal analgesia in genetically epilepsy-prone rats is induced by audiogenic seizures and involves cannabinoid receptors in the periaqueductal gray. Brain Res 2011;1389:177-182.

128. Bhaskaran MD, Smith BN. Cannabinoid-mediated inhibition of recurrent excitatory circuitry in the dentate gyrus in a mouse model of temporal lobe epilepsy. PloS One 2010;5:e10683.

129. Chen C-Y, Li W, Qu K-P, Chen C-R. Piperine exerts anti-seizure effects via the TRPV1 receptor in mice. Eur J Pharmacol 2013;714:288-294.

130. Ghazizadeh V, Nazıroğlu M. Electromagnetic radiation (Wi-Fi) and epilepsy induce calcium entry and apoptosis through activation of TRPV1 channel in hippocampus and dorsal root ganglion of rats. Metab Brain Dis 2014;29:787-799.

131. Gonzalez-Reyes LE, Ladas TP, Chiang C-C, Durand DM. TRPV1 antagonist capsazepine suppresses 4-AP-induced epileptiform activity in vitro and electrographic seizures in vivo. Exp Neurol 2013;250:321-332.

132. Manna SSS, Umathe SN. Involvement of transient receptor potential vanilloid type 1 channels in the pro-convulsant effect of anandamide in pentylenetetrazole-induced seizures. Epilepsy Res 2012;100:113-124.

133. Nazıroğlu M, Özkan FF, Hapil SR, Ghazizadeh V, Çiğ B. Epilepsy but not mobile phone frequency $(900 \mathrm{MHz})$ induces apoptosis and calcium entry in hippocampus of epileptic rat: involvement of TRPV1 channels. J Membr Biol 2015;248: 83-91.

134. Shirazi M, Izadi M, Amin M, Rezvani ME, Roohbakhsh A, Shamsizadeh A. Involvement of central TRPV1 receptors in pentylenetetrazole and amygdala-induced kindling in male rats. Neurol Sci 2014;35:1235-1241.

135. Kong W-L, Min J-W, Liu Y-L, Li J-X, He X-H, Peng B-W. Role of TRPV1 in susceptibility to PTZ-induced seizure following repeated hyperthermia challenges in neonatal mice. Epilepsy Behav 2014;31:276-280.

136. Hunt RF, Hortopan GA, Gillespie A, Baraban SC. A novel zebrafish model of hyperthermia-induced seizures reveals a role for TRPV4 channels and NMDA-type glutamate receptors. Exp Neurol 2012;237:199-206.

137. Lin Y-W, Hsieh C-L. Auricular electroacupuncture reduced inflammation-related epilepsy accompanied by altered TRPA1, $\mathrm{pPKC} \alpha, \mathrm{pPKC} \varepsilon$, and $\mathrm{pERk} 1 / 2$ signaling pathways in kainic acid-treated rats. Mediators Inflamm 2014;2014:493480.

138. Brinckmann A, Weiss C, Wilbert F, et al. Regionalized pathology correlates with augmentation of mtDNA copy numbers in a patient with myoclonic epilepsy with ragged-red fibers (MERRF-syndrome). PloS One 2010;5:e13513.

139. Jiang W, Du B, Chi Z, et al. Preliminary explorations of the role of mitochondrial proteins in refractory epilepsy: some findings from comparative proteomics. J Neurosci Res 2007;85:3160-3170.

140. Quintanilla RA, Utreras E, Cabezas-Opazo FA. Role of PPAR $\gamma$ in the differentiation and function of neurons. PPAR Res 2014;2014: 768594.

141. Lasoń W, Chlebicka M, Rejdak K. Research advances in basic mechanisms of seizures and antiepileptic drug action. Pharmacol Rep 2013;65:787-801.

142. Adams PJ, Snutch TP. Calcium channelopathies: voltage-gated calcium channels. Subcell Biochem 2007;45:215-251.

143. Gomora JC, Daud AN, Weiergräber M, Perez-Reyes E. Block of cloned human T-type calcium channels by succinimide antiepileptic drugs. Mol Pharmacol 2001;60:1121-1132.

144. Ceulemans B, Boel M, Leyssens K, et al. Successful use of fenfluramine as an add-on treatment for Dravet syndrome. Epilepsia 2012;53:1131-1139.

145. Theodore WH, Hasler G, Giovacchini G, et al. Reduced hippocampal 5HT1A PET receptor binding and depression in temporal lobe epilepsy. Epilepsia 2007;48:1526-1530.

146. Theodore WH, Wiggs EA, Martinez AR, et al. Serotonin 1A receptors, depression, and memory in temporal lobe epilepsy. Epilepsia 2012;53:129-133.

147. Avila A, Nguyen L, Rigo J-M. Glycine receptors and brain development. Front Cell Neurosci 2013;7:184.

148. Harvey RJ, Carta E, Pearce BR, et al. A critical role for glycine transporters in hyperexcitability disorders. Front Mol Neurosci 2008;1:1.

149. Chu Sin Chung P, Kieffer BL. Delta opioid receptors in brain function and diseases. Pharmacol Ther 2013;140:112-120.

150. Snead OC. Opiate-induced seizures: a study of mu and delta specific mechanisms. Exp Neurol 1986;93:348-358.

151. Sagratella S, Scotti de Carolis A. In vivo and in vitro epileptogenic effects of the enkephalinergic system. Ann Ist Super Sanita 1993;29:413-418.

152. Saghazadeh A, Mastrangelo M, Rezaei N. Genetic background of febrile seizures. Rev Neurosci 2014;25:129-161. 
153. Becchetti A, Aracri P, Meneghini S, Brusco S, Amadeo A. The role of nicotinic acetylcholine receptors in autosomal dominant nocturnal frontal lobe epilepsy. Front Physiol 2015;6:22.

154. Dias RB, Rombo DM, Ribeiro JA, Henley JM, Sebastião AM. Adenosine: setting the stage for plasticity. Trends Neurosci 2013;36:248-257.

155. Świąder MJ, Kotowski J, Łuszczki JJ. Modulation of adenosinergic system and its application for the treatment of epilepsy. Pharmacol Rep 2014;66:335-342.

156. Hedlund E, Gustafsson JA, Warner M. Cytochrome P450 in the brain; a review. Curr Drug Metab 2001;2:245-263.

157. Adibhatla RM, Hatcher JF. Altered lipid metabolism in brain injury and disorders. Subcell Biochem 2008;49:241-268.

158. Coomber B, O'Donoghue MF, Mason R. Inhibition of endocannabinoid metabolism attenuates enhanced hippocampal neuronal activity induced by kainic acid. Synapse 2008;62:746755.

159. Vilela LR, Medeiros DC, Rezende GHS, de Oliveira ACP, Moraes MFD, Moreira FA. Effects of cannabinoids and endocannabinoid hydrolysis inhibition on pentylenetetrazole-induced seizure and electroencephalographic activity in rats. Epilepsy Res 2013;104: 195-202.

160. Villikka K, Kivistö KT, Mäenpää H, Joensuu H, Neuvonen PJ. Cytochrome P450-inducing antiepileptics increase the clearance of vincristine in patients with brain tumors. Clin Pharmacol Ther 1999;66:589-593.

161. Geffrey AL, Pollack SF, Bruno PL, Thiele EA. Drug-drug interaction between clobazam and cannabidiol in children with refractory epilepsy. Epilepsia 2015 Jun 26 [Epub ahead of print].

162. Clinckers R, Smolders I, Meurs A, Ebinger G, Michotte Y. Anticonvulsant action of hippocampal dopamine and serotonin is independently mediated by D and 5 -HT receptors. J Neurochem 2004;89:834-843.

163. Zoerner AA, Gutzki F-M, Batkai S, et al. Quantification of endocannabinoids in biological systems by chromatography and mass spectrometry: a comprehensive review from an analytical and biological perspective. Biochim Biophys Acta 2011;1811: 706-723.

164. Dawbarn D, Harmar AJ, Pycock CJ. Intranigral injection of capsaicin enhances motor activity and depletes nigral 5hydroxytryptamine but not substance P. Neuropharmacology 1981;20:341-346.

165. Hajós M, Engberg G, Nissbrandt H, Magnusson T, Carlsson A. Capsaicin-sensitive vasodilatatory mechanisms in the rat substantia nigra and striatum. J Neural Transm 1988;74:129139.

166. Geisler S, Holmström KM, Skujat D, et al. PINK1/Parkinmediated mitophagy is dependent on VDAC1 and p62/ SQSTM1. Nat Cell Biol 2010;12:119-131.

167. Stone JM, Day F, Tsagaraki H, et al. Glutamate dysfunction in people with prodromal symptoms of psychosis: relationship to gray matter volume. Biol Psychiatry 2009;66:533-539.

168. Sramek JJ, Tansman M, Suri A, et al. Efficacy of buspirone in generalized anxiety disorder with coexisting mild depressive symptoms. J Clin Psychiatry 1996;57:287-291.

169. Bourin M, Nic Dhonnchadha BA. 5-HT2 receptors and anxiety. Drug Dev Res 2005;65:133-140.

170. Bush A, Busst CM, Clarke B, Barnes PJ. Effect of infused adenosine on cardiac output and systemic resistance in normal subjects. Br J Clin Pharmacol 1989;27:165-171.

171. Litvin Y, Phan A, Hill MN, Pfaff DW, McEwen BS. CB1 receptor signaling regulates social anxiety and memory. Genes Brain Behav 2013;12:479-489.

172. Mohajjel Nayebi A A, Sheidaei H. Buspirone improves haloperidol-induced Parkinson disease in mice through 5-HT1A receptors. Daru 2010;18:41-45.
173. Becker CM, Hermans-Borgmeyer I, Schmitt B, Betz H. The glycine receptor deficiency of the mutant mouse spastic: evidence for normal glycine receptor structure and localization. J Neurosci 1986;6:1358-1364.

174. Henry B, Fox SH, Crossman AR, Brotchie JM. Mu- and deltaopioid receptor antagonists reduce levodopa-induced dyskinesia in the MPTP-lesioned primate model of Parkinson's disease. Exp Neurol 2001;171:139-146.

175. Patsopoulos NA, Ntzani EE, Zintzaras E, Ioannidis JPA. CYP2D6 polymorphisms and the risk of tardive dyskinesia in schizophrenia: a meta-analysis. Pharmacogenet Genomics 2005;15:151-158.

176. Liévens JC, Woodman B, Mahal A, et al. Impaired glutamate uptake in the R6 Huntington's disease transgenic mice. Neurobiol Dis 2001;8:807-821.

177. Kanyó B, Argyelán M, Dibó G, et al. [Imaging of dopamine transporter with Tc99m-Trodat-SPECT in movement disorders]. Ideggyogy Sz 2003;56:231-240 (in Hungarian).

178. de Lago E, Fernández-Ruiz J, Ortega-Gutiérrez S, et al. UCM707, an inhibitor of the anandamide uptake, behaves as a symptom control agent in models of Huntington's disease and multiple sclerosis, but fails to delay/arrest the progression of different motorrelated disorders. Eur Neuropsychopharmacol 2006;16:7-18.

179. Pamplona FA, Ferreira J, Lima OM de, et al. Anti-inflammatory lipoxin A4 is an endogenous allosteric enhancer of CB1 cannabinoid receptor. Proc Natl Acad Sci 2012;109:21134-21139.

180. Daigle TL, Kearn CS, Mackie K. Rapid CB1 cannabinoid receptor desensitization defines the time course of ERK1/2 MAP kinase signaling. Neuropharmacology 2008;54:36-44.

181. Aso E, Sánchez-Pla A, Vegas-Lozano E, Maldonado R, Ferrer I. Cannabis-based medicine reduces multiple pathological processes in A $\beta$ PP/PS1 mice. J Alzheimers Dis 2015;43:977-991.

182. Cheng D, Spiro AS, Jenner AM, Garner B, Karl T. Long-term cannabidiol treatment prevents the development of social recognition memory deficits in Alzheimer's disease transgenic mice. J Alzheimers Dis 2014;42:1383-1396.

183. Calì T, Ottolini D, Brini M. Mitochondrial Ca2+ and neurodegeneration. Cell Calcium 2012;52:73-85.

184. Currais A. Ageing and inflammation - a central role for mitochondria in brain health and disease. Ageing Res Rev 2015;21:30-42.

185. Hsieh H-L, Yang C-M. Role of redox signaling in neuroinflammation and neurodegenerative diseases. Biomed Res Int 2013;2013:484613.

186. Sosa-Ortiz AL, Acosta-Castillo I, Prince MJ. Epidemiology of dementias and Alzheimer's disease. Arch Med Res 2012;43:600608.

187. Hardy JA, Higgins GA. Alzheimer's disease: the amyloid cascade hypothesis. Science 1992;256:184-185.

188. Latta CH, Brothers HM, Wilcock DM. Neuroinflammation in Alzheimer's disease; a source of heterogeneity and target for personalized therapy. Neuroscience 2014;pii:S0306-4522(14)008203.

189. Lozano D, Gonzales-Portillo GS, Acosta S, et al. Neuroinflammatory responses to traumatic brain injury: etiology, clinical consequences, and therapeutic opportunities. Neuropsychiatr Dis Treat 2015;11:97-106.

190. Ruhoy IS, Saneto RP. The genetics of Leigh syndrome and its implications for clinical practice and risk management. Appl Clin Genet 2014;7:221-234.

191. Heneka MT, Carson MJ, Khoury J El, et al. Neuroinflammation in Alzheimer's disease. Lancet Neurol 2015;14:388-405.

192. Di Iorio G, Lupi M, Sarchione F, et al. The endocannabinoid system: a putative role in neurodegenerative diseases. Int J High Risk Behav Addict 2013;2:100-106.

193. Maroof N, Pardon MC, Kendall DA. Endocannabinoid signalling in Alzheimer's disease. Biochem Soc Trans 2013;41:1583-1587. 
194. Elmes MW, Kaczocha M, Berger WT, et al. Fatty acid-binding proteins (FABPs) are intracellular carriers for $\Delta 9$-tetrahydrocannabinol (THC) and cannabidiol (CBD). J Biol Chem 2015;290: 8711-8721.

195. Xu Y, Yan J, Zhou P, et al. Neurotransmitter receptors and cognitive dysfunction in Alzheimer's disease and Parkinson's disease. Prog Neurobiol 2012;97:1-13.

196. Magen I, Avraham Y, Ackerman Z, Vorobiev L, Mechoulam R, Berry EM. Cannabidiol ameliorates cognitive and motor impairments in bile-duct ligated mice via 5-HT1A receptor activation. Br J Pharmacol 2010;159:950-957.

197. Pazos MR, Mohammed N, Lafuente H, et al. Mechanisms of cannabidiol neuroprotection in hypoxic-ischemic newborn pigs: role of $5 \mathrm{HT}(1 \mathrm{~A})$ and $\mathrm{CB} 2$ receptors. Neuropharmacology 2013;71:282-291.

198. Esposito G, Scuderi C, Valenza M, et al. Cannabidiol reduces A $\beta$ induced neuroinflammation and promotes hippocampal neurogenesis through PPAR $\gamma$ involvement. PloS One 2011;6: e28668.

199. Cho H-Y, Gladwell W, Wang X, et al. Nrf2-regulated PPAR \{gamma\} expression is critical to protection against acute lung injury in mice. Am J Respir Crit Care Med 2010;182:170182.

200. Juknat A, Pietr M, Kozela E, et al. Differential transcriptional profiles mediated by exposure to the cannabinoids cannabidiol and $\Delta$ 9-tetrahydrocannabinol in BV-2 microglial cells. Br J Pharmacol 2012;165:2512-2528.

201. Lauckner JE, Jensen JB, Chen H-Y, Lu H-C, Hille B, Mackie K. GPR55 is a cannabinoid receptor that increases intracellular calcium and inhibits M current. Proc Natl Acad Sci U S A 2008;105: 2699-2704.

202. Henstridge CM, Balenga NAB, Ford LA, Ross RA, Waldhoer M, Irving AJ. The GPR55 ligand L-alpha-lysophosphatidylinositol promotes RhoA-dependent $\mathrm{Ca} 2+$ signaling and NFAT activation. FASEB J 2009;23:183-193.

203. Fric J, Zelante T, Wong AYW, Mertes A, Yu H-B, RicciardiCastagnoli P. NFAT control of innate immunity. Blood 2012;120:1380-1389.

204. Vashishta A, Habas A, Pruunsild P, Zheng J-J, Timmusk T, Hetman M. Nuclear factor of activated T-cells isoform c4 (NFATc4/NFAT3) as a mediator of antiapoptotic transcription in NMDA receptor-stimulated cortical neurons. J Neurosci 2009;29: 15331-15340.

205. Wu H-Y, Hudry E, Hashimoto T, et al. Amyloid beta induces the morphological neurodegenerative triad of spine loss, dendritic simplification, and neuritic dystrophies through calcineurin activation. J Neurosci 2010;30:2636-2649.

206. Abdul HM, Sama MA, Furman JL, et al. Cognitive decline in Alzheimer's disease is associated with selective changes in calcineurin/NFAT signaling. J Neurosci 2009;29:12957-12969.

207. Deutsch SI, Burket JA, Benson AD. Targeting the $\alpha 7$ nicotinic acetylcholine receptor to prevent progressive dementia and improve cognition in adults with Down's syndrome. Prog Neuropsychopharmacol Biol Psychiatry 2014;54:131-139.

208. Lombardo S, Maskos U. Role of the nicotinic acetylcholine receptor in Alzheimer's disease pathology and treatment. Neuropharmacology 2015;96(Pt B):255-262.

209. Vaysse PJ, Gardner EL, Zukin RS. Modulation of rat brain opioid receptors by cannabinoids. J Pharmacol Exp Ther 1987;241:534539

210. Feng Y, He X, Yang Y, Chao D, Lazarus LH, Xia Y. Current research on opioid receptor function. Curr Drug Targets 2012;13:230-246.

211. Hroudová J, Singh N, Fišar Z. Mitochondrial dysfunctions in neurodegenerative diseases: relevance to Alzheimer's disease. Biomed Res Int 2014;175062.
212. Ristow M, Schmeisser K. Mitohormesis: promoting health and lifespan by increased levels of reactive oxygen species (ROS). Dose Response 2014;12:288-341.

213. Tapia PC. Sublethal mitochondrial stress with an attendant stoichiometric augmentation of reactive oxygen species may precipitate many of the beneficial alterations in cellular physiology produced by caloric restriction, intermittent fasting, exercise and dietary phytonutrients: "Mitohormesis" for health and vitality. Med Hypotheses 2006;66:832-843.

214. Myint A-M, Kim Y-K. Network beyond IDO in psychiatric disorders: revisiting neurodegeneration hypothesis. Prog Neuropsychopharmacol Biol Psychiatry 2014;48:304-313.

215. Figueiredo-Pereira ME, Rockwell P, Schmidt-Glenewinkel T, Serrano P. Neuroinflammation and J2 prostaglandins: linking impairment of the ubiquitin-proteasome pathway and mitochondria to neurodegeneration. Front Mol Neurosci 2014;7:104.

216. Calder PC. Marine omega-3 fatty acids and inflammatory processes: Effects, mechanisms and clinical relevance. Biochim Biophys Acta 2015;1851:469-484.

217. Pomponi MFL, Gambassi G, Pomponi M, Di Gioia A, Masullo C. Why docosahexaenoic acid and aspirin supplementation could be useful in women as a primary prevention therapy against Alzheimer's disease? Ageing Res Rev 2011;10:124-131.

218. Hamelink C, Hampson A, Wink DA, Eiden LE, Eskay RL. Comparison of cannabidiol, antioxidants, and diuretics in reversing binge ethanol-induced neurotoxicity. J Pharmacol Exp Ther 2005;314:780-788.

219. Hampson AJ, Grimaldi M, Axelrod J, Wink D. Cannabidiol and ()Delta9-tetrahydrocannabinol are neuroprotective antioxidants. Proc Natl Acad Sci U S A 1998;95:8268-8273.

220. García-Arencibia M, González S, de Lago E, Ramos JA, Mechoulam R, Fernández-Ruiz J. Evaluation of the neuroprotective effect of cannabinoids in a rat model of Parkinson's disease: importance of antioxidant and cannabinoid receptor-independent properties. Brain Res 2007;1134:162-170.

221. Itoh K, Chiba T, Takahashi S, et al. An Nrf2/small Maf heterodimer mediates the induction of phase II detoxifying enzyme genes through antioxidant response elements. Biochem Biophys Res Commun 1997;236:313-322.

222. Mazur A, Lichti CF, Prather PL, et al. Characterization of human hepatic and extrahepatic UDP-glucuronosyltransferase enzymes involved in the metabolism of classic cannabinoids. Drug Metab Dispos Biol Fate Chem 2009;37:1496-1504.

223. Fernández-Ruiz J, Sagredo O, Pazos MR, et al. Cannabidiol for neurodegenerative disorders: important new clinical applications for this phytocannabinoid? Br J Clin Pharmacol 2013;75:323-333.

224. Reddy $\mathrm{PH}$. Is the mitochondrial outermembrane protein VDAC1 therapeutic target for Alzheimer's disease? Biochim Biophys Acta 2013;1832:67-75.

225. Manczak M, Sheiko T, Craigen WJ, Reddy PH. Reduced VDAC1 protects against Alzheimer's disease, mitochondria, and synaptic deficiencies. J Alzheimers Dis 2013;37:679-690.

226. Keinan N, Pahima H, Ben-Hail D, Shoshan-Barmatz V. The role of calcium in VDAC1 oligomerization and mitochondriamediated apoptosis. Biochim Biophys Acta 2013;1833:17451754.

227. De Stefani D, Bononi A, Romagnoli A, et al. VDAC1 selectively transfers apoptotic $\mathrm{Ca} 2+$ signals to mitochondria. Cell Death Differ 2012;19:267-273.

228. Mato S, Victoria Sánchez-Gómez M, Matute C. Cannabidiol induces intracellular calcium elevation and cytotoxicity in oligodendrocytes. Glia 2010;58:1739-1747.

229. Ryan D, Drysdale AJ, Lafourcade C, Pertwee RG, Platt B. Cannabidiol targets mitochondria to regulate intracellular $\mathrm{Ca} 2+$ levels. J Neurosci 2009;29:2053-2063. 
230. Ho KW, Ward NJ, Calkins DJ. TRPV1: a stress response protein in the central nervous system. Am J Neurodegener Dis 2012;1:114.

231. Luo Z, Ma L, Zhao Z, et al. TRPV1 activation improves exercise endurance and energy metabolism through PGC- $1 \alpha$ upregulation in mice. Cell Res 2012;22:551-564.

232. Medvedeva YV, Kim M-S, Usachev YM. Mechanisms of prolonged presynaptic $\mathrm{Ca} 2+$ signaling and glutamate release induced by TRPV1 activation in rat sensory neurons. J Neurosci 2008;28:5295-5311.

233. Gellerich FN, Gizatullina Z, Gainutdinov T, et al. The control of brain mitochondrial energization by cytosolic calcium: the mitochondrial gas pedal. IUBMB Life 2013;65:180-190.

234. Gupta S, Sharma B. Pharmacological benefits of agomelatine and vanillin in experimental model of Huntington's disease. Pharmacol Biochem Behav 2014;122:122-135.

235. Gomes CV, Kaster MP, Tomé AR, Agostinho PM, Cunha RA. Adenosine receptors and brain diseases: neuroprotection and neurodegeneration. Biochim Biophys Acta 2011;1808:1380-1399.

236. Smathers RL, Petersen DR. The human fatty acid-binding protein family: evolutionary divergences and functions. Hum Genomics 2011;5:170-191.

237. Ohrfelt A, Andreasson U, Simon A, et al. Screening for new biomarkers for subcortical vascular dementia and Alzheimer's disease. Dement Geriatr Cogn Disord Extra 2011;1:31-42.

238. Shioda N, Yabuki Y, Kobayashi Y, Onozato M, Owada Y, Fukunaga K. FABP3 protein promotes $\alpha$-synuclein oligomerization associated with 1-methyl-1,2,3,6-tetrahydropiridine-induced neurotoxicity. J Biol Chem 2014;289:18957-18965.

239. Pahnke J, Fröhlich C, Krohn M, Schumacher T, Paarmann K. Impaired mitochondrial energy production and $\mathrm{ABC}$ transporter function-A crucial interconnection in dementing proteopathies of the brain. Mech Ageing Dev 2013;134:506-515.

240. Krohn M, Lange C, Hofrichter J, et al. Cerebral amyloid- $\beta$ proteostasis is regulated by the membrane transport protein ABCC1 in mice. J Clin Invest 2011;121:3924-3931.

241. Xiong H, Callaghan D, Jones A, et al. ABCG2 is upregulated in Alzheimer's brain with cerebral amyloid angiopathy and may act as a gatekeeper at the blood-brain barrier for Abeta(1-40) peptides. J Neurosci 2009;29:5463-5475.

242. Martorana A, Koch G. Is dopamine involved in Alzheimer's disease? Front Aging Neurosci 2014;6:252.

243. Caraci F, Battaglia G, Sortino MA, et al. Metabotropic glutamate receptors in neurodegeneration/neuroprotection: still a hot topic? Neurochem Int 2012;61:559-565.

244. Lund-Katz S, Phillips MC. High density lipoprotein structurefunction and role in reverse cholesterol transport. Subcell Biochem 2010;51:183-227.

245. Poirier J, Miron J, Picard C, et al. Apolipoprotein E and lipid homeostasis in the etiology and treatment of sporadic Alzheimer's disease. Neurobiol Aging 2014;35(Suppl. 2):S3-S10.

246. Benyamin R, Trescot AM, Datta S, et al. Opioid complications and side effects. Pain Physician 2008;11(2 Suppl.):S105-S120.

247. Sindrup SH, Jensen TS. Efficacy of pharmacological treatments of neuropathic pain: an update and effect related to mechanism of drug action. Pain 1999;83:389-400.

248. Costa B, Giagnoni G, Franke C, Trovato AE, Colleoni M. Vanilloid TRPV1 receptor mediates the antihyperalgesic effect of the nonpsychoactive cannabinoid, cannabidiol, in a rat model of acute inflammation. Br J Pharmacol 2004;143:247-250

249. Costa B, Trovato AE, Comelli F, Giagnoni G, Colleoni M. The non-psychoactive cannabis constituent cannabidiol is an orally effective therapeutic agent in rat chronic inflammatory and neuropathic pain. Eur J Pharmacol 2007;556:75-83.

250. Maione S, Piscitelli F, Gatta L, et al. Non-psychoactive cannabinoids modulate the descending pathway of antinociception in anaesthetized rats through several mechanisms of action. Br J Pharmacol 2011;162:584-596.

251. Ward SJ, Ramirez MD, Neelakantan H, Walker EA. Cannabidiol prevents the development of cold and mechanical allodynia in paclitaxel-treated female C57B16 mice. Anesth Analg 2011;113: 947-950.

252. Ward SJ, McAllister SD, Kawamura R, Murase R, Neelakantan H, Walker EA. Cannabidiol inhibits paclitaxel-induced neuropathic pain through 5-HT(1A) receptors without diminishing nervous system function or chemotherapy efficacy. Br J Pharmacol 2014; 171:636-645.

253. Sałat K, Filipek B. Antinociceptive activity of transient receptor potential channel TRPV1, TRPA1, and TRPM8 antagonists in neurogenic and neuropathic pain models in mice. J Zhejiang Univ Sci B 2015;16:167-178.

254. Costa B, Siniscalco D, Trovato AE, et al. AM404, an inhibitor of anandamide uptake, prevents pain behaviour and modulates cytokine and apoptotic pathways in a rat model of neuropathic pain. $\mathrm{Br}$ J Pharmacol 2006;148:1022-1032.

255. Lehto SG, Weyer AD, Zhang M, et al. AMG2850, a potent and selective TRPM8 antagonist, is not effective in rat models of inflammatory mechanical hypersensitivity and neuropathic tactile allodynia. Naunyn Schmiedebergs Arch Pharmacol 2015;388: 465-476.

256. Baddack U, Frahm S, Antolin-Fontes B, et al. Suppression of peripheral pain by blockade of Cav2.2 channels in nociceptors induces RANKL and impairs recovery from inflammatory arthritis. Arthritis Rheumatol 2015;67:1657-1667.

257. Jayamanne A, Jeong HJ, Schroeder CI, Lewis RJ, Christie MJ, Vaughan CW. Spinal actions of $\omega$-conotoxins, CVID, MVIIA and related peptides in a rat neuropathic pain model. Br J Pharmacol 2013;170:245-254.

258. Gao X, Lu Q, Chou G, et al. Norisoboldine attenuates inflammatory pain via the adenosine A1 receptor. Eur J Pain 2014;18:939948.

259. Li L, Hao JX, Fredholm BB, Schulte G, Wiesenfeld-Hallin Z, Xu $X J$. Peripheral adenosine A2A receptors are involved in carrageenan-induced mechanical hyperalgesia in mice. Neuroscience 2010;170:923-928.

260. Fornal CA, Metzler CW, Gallegos RA, Veasey SC, McCreary AC, Jacobs BL. WAY-100635, a potent and selective 5hydroxytryptamine1 A antagonist, increases serotonergic neuronal activity in behaving cats: comparison with (S)-WAY-100135. J Pharmacol Exp Ther 1996;278:752-762.

261. Staton PC, Hatcher JP, Walker DJ, et al. The putative cannabinoid receptor GPR55 plays a role in mechanical hyperalgesia associated with inflammatory and neuropathic pain. Pain 2008;139:225236.

262. Terrando N, Yang T, Ryu JK, et al. Stimulation of the alpha 7 nicotinic acetylcholine receptor protects against neuroinflammation after tibia fracture and endotoxemia in mice. Mol Med 2015;20:667-675.

263. AlSharari SD, Freitas K, Damaj MI. Functional role of alpha7 nicotinic receptor in chronic neuropathic and inflammatory pain: Studies in transgenic mice. Biochem Pharmacol 2013;86:12011207.

264. Gong S, Liang Q, Zhu Q, et al. Nicotinic acetylcholine receptor $\alpha 7$ subunit is involved in the cobratoxin-induced antinociception in an animal model of neuropathic pain. Toxicon 2015;93:31-36.

265. Papke RL, Bagdas D, Kulkarni AR, et al. The analgesic-like properties of the alpha7 nAChR silent agonist NS6740 is associated with non-conducting conformations of the receptor. Neuropharmacology 2015;91:34-42.

266. Hasani R Al-, Bruchas MR. Molecular mechanisms of opioid receptor-dependent signaling and behavior. Anesthesiology 2011;115:1363-1381. 
267. Vowles KE, McEntee ML, Julnes PS, Frohe T, Ney JP, van der Goes DN. Rates of opioid misuse, abuse, and addiction in chronic pain: a systematic review and data synthesis. Pain 2015;156:569576.

268. Zahari Z, Ismail R. Influence of Cytochrome P450, family 2, subfamily D, polypeptide 6 (CYP2D6) polymorphisms on pain sensitivity and clinical response to weak opioid analgesics. Drug Metab Pharmacokinet 2014;29:29-43.

269. Campos AC, Guimarães FS. Evidence for a potential role for TRPV1 receptors in the dorsolateral periaqueductal gray in the attenuation of the anxiolytic effects of cannabinoids. Prog Neuropsychopharmacol Biol Psychiatry 2009;33:1517-1521.

270. Moussaieff A, Rimmerman N, Bregman T, et al. Incensole acetate, an incense component, elicits psychoactivity by activating TRPV3 channels in the brain. FASEB J 2008;22:3024-3034.

271. Uslaner JM, Smith SM, Huszar SL, et al. T-type calcium channel antagonism produces antipsychotic-like effects and reduces stimulant-induced glutamate release in the nucleus accumbens of rats. Neuropharmacology 2012;62:1413-1421.

272. Gangarossa G, Laffray S, Bourinet E, Valjent E. T-type calcium channel Cav3.2 deficient mice show elevated anxiety, impaired memory and reduced sensitivity to psychostimulants. Front Behav Neurosci 2014;8:92.

273. Price DL, Bonhaus DW, McFarland K. Pimavanserin, a 5-HT2A receptor inverse agonist, reverses psychosis-like behaviors in a rodent model of Alzheimer's disease. Behav Pharmacol 2012;23: 426-433.

274. Zhang CG, Kim S-J. Taurine induces anti-anxiety by activating strychnine-sensitive glycine receptor in vivo. Ann Nutr Metab 2007;51:379-386.

275. Randall-Thompson JF, Pescatore KA, Unterwald EM. A role for delta opioid receptors in the central nucleus of the amygdala in anxiety-like behaviors. Psychopharmacology 2010;212:585-595.

276. Rahimi A, Hajizadeh Moghaddam A, Roohbakhsh A. Central administration of GPR55 receptor agonist and antagonist modulates anxiety-related behaviors in rats. Fundam Clin Pharmacol 2015;29:185-190.

277. Maximino C, Lima MG, Olivera KRM, Picanço-Diniz DLW, Herculano AM. Adenosine A1, but not A2, receptor blockade increases anxiety and arousal in Zebrafish. Basic Clin Pharmacol Toxicol 2011;109:203-207.
278. Shen H-Y, Singer P, Lytle N, et al. Adenosine augmentation ameliorates psychotic and cognitive endophenotypes of schizophrenia. J Clin Invest 2012;122:2567-2577.

279. Müller N. COX-2 inhibitors as antidepressants and antipsychotics: clinical evidence. Curr Opin Investig Drugs 2010;11:31-42.

280. Hill MN, Kumar SA, Filipski SB, et al. Disruption of fatty acid amide hydrolase activity prevents the effects of chronic stress on anxiety and amygdalar microstructure. Mol Psychiatry 2013;18:1125-1135.

281. Leweke FM, Piomelli D, Pahlisch F, et al. Cannabidiol enhances anandamide signaling and alleviates psychotic symptoms of schizophrenia. Transl Psychiatry 2012;2:e94.

282. Stangherlin EC, Nogueira CW. Diphenyl ditelluride induces anxiogenic-like behavior in rats by reducing glutamate uptake. Biol Trace Elem Res 2014;158:392-398.

283. Morgan CJA, Das RK, Joye A, Curran HV, Kamboj SK. Cannabidiol reduces cigarette consumption in tobacco smokers: preliminary findings. Addict Behav 2013;38:2433-2436.

284. Ren Y, Whittard J, Higuera-Matas A, Morris CV, Hurd YL. Cannabidiol, a nonpsychotropic component of cannabis, inhibits cue-induced heroin seeking and normalizes discrete mesolimbic neuronal disturbances. J Neurosci 2009;29:14764-14769.

285. Adamczyk P, Miszkiel J, McCreary AC, Filip M, Papp M, Przegaliński E. The effects of cannabinoid CB1, CB2 and vanilloid TRPV1 receptor antagonists on cocaine addictive behavior in rats. Brain Res 2012;1444:45-54.

286. Heng L-J, Huang B, Guo H, et al. Blocking TRPV1 in nucleus accumbens inhibits persistent morphine conditioned place preference expression in rats. PloS One 2014;9:e104546.

287. Shapovalov G, Gkika D, Devilliers M, et al. Opiates modulate thermosensation by internalizing cold receptor TRPM8. Cell Rep 2013;4:504-515.

288. Tyndale RF, Droll KP, Sellers EM. Genetically deficient CYP2D6 metabolism provides protection against oral opiate dependence. Pharmacogenetics 1997;7:375-379.

289. Miksys S, Rao Y, Hoffmann E, Mash DC, Tyndale RF. Regional and cellular expression of CYP2D6 in human brain: higher levels in alcoholics. J Neurochem 2002;82:1376-1387.

290. Tournier N, Chevillard L, Megarbane B, Pirnay S, Scherrmann J$M$, Declèves X. Interaction of drugs of abuse and maintenance treatments with human P-glycoprotein (ABCB1) and breast cancer resistance protein (ABCG2). Int J Neuropsychopharmacol 2010;13:905-915. 